\title{
El bautismo de esclavos, libertos y musulmanes libres en el Orán de Felipe II*
}

\author{
Juan Jesús Bravo Caro \\ Universidad de Málaga
}

RESUMEN: El objetivo principal del artículo es presentar nuevos datos sobre el volumen de bautizos y conversiones oficiadas en Orán durante el último tercio del siglo XVI. La documentación parroquial conservada de ese periodo constituye la fuente básica de análisis, complementada con información emanada de distintas instituciones que conformaban el organigrama de gestión y gobierno de la España del quinientos. Su categorización de plaza en frontera le va a conferir una especificidad, también en la cuestión de presencia esclava, respecto a otras poblaciones de la Monarquia Hispánica en la Península Ibérica y en territorios insulares dependientes de ella. El porcentaje de personas esclavizadas o libertas que acceden al sacramento del bautismo es superior al registrado en muchas ciudades españolas de la época, para los años estudiados. Además, diferentes miembros de familias musulmanas o judías contemplarán esta fórmula de ingreso confesional como vía de inicio en una integración social, o al menos de vehiculo a la hora de materializar su existencia en la sociedad española de la época, ya fuera en África o la metrópoli. La referencia a los propietarios muestra, al igual que en el resto de núcleos de población examinados, una participación de diversos colectivos en el mercado de esclavos.

\section{PAlabRas Clave: Orán; Mediterráneo; esclavitud; conversiones; re- gistros parroquiales; siglo XVI.}

The Baptism of Slaves, Freedmen and Free Muslims in the Oran of Philip II

* Siglas: ADT: Archivo Diocesano de Toledo; AGI: Archivo General de Indias; AGS: Archivo General de Simancas; CRC: Consejo Real de Castilla; ARChG: Archivo de la Real Chancillería de Granada; AMM: Archivo Municipal de Málaga; BNE: Biblioteca Nacional de España; BRAH: Biblioteca de la Real Academia de la Historia. 


\begin{abstract}
The main objective of the article is to present new data on the volume of baptisms and conversions officiated in Oran during the last third of the sixteenth century. The parish documents preserved from this period are the basic source of analysis, supplemented by information emanating from different institutions that comprise the organizational management and administration of the Spain of XVI century. The categorization of Oran as a square border is going to confer specificity, also in the matter of slave presence, compared to other populations in the Spanish Monarchy in the Iberian Peninsula and island territories dependent on it. The percentage of enslaved people or freedmen entering the sacrament of baptism is higher than in many Spanish cities at the time, for the years studied. In addition, various members of Muslim families or Jewish religious contemplate this formula of conffesional income as a social integration via, or at least, a vehicle in realizing their existence in the Spanish society of the time, whether in Africa or the metropoli. As in other towns examined, the reference to the owners shows a participation of various groups in the slave market.
\end{abstract}

KEY WORDS: Oran; Mediterranean; slavery; conversions; parish registers; 16th century.

\title{
INTRODUCCIÓN
}

Al tomar Orán en 1509 comenzaba una etapa de más de dos siglos, en los que la ciudad desempeñaría un papel muy importante en la estrategia hispana de mantener emplazamientos en el norte de África ${ }^{1}$. La bibliografía editada hasta el momento recoge una gran variedad temática que abarca los diversos aspectos de índole militar, política, económica y social de esa dilatada etapa secular. Relacionado con estos dos últimos aspectos tendríamos el fenómeno de la esclavitud. Abordada en el marco de cuestiones más generales, comienza a ser más conocida a partir de estudios específicos sobre el colectivo.

La presencia española en la franja costera septentrional africana se limitaba a unas plazas de desigual dimensión, que respondían a lo calificado a principios del siglo XX de ocupación restringida y que indicaba su similitud a la de los portugueses en el área marroquí, al menos hasta 1830, e intentaba explicar el alcance de la dominación de aquellos territorios por lusos e hispanos: "on attribue généralement cet échec à la politique d'occupation restreinte"2. Las diferencias respecto a la estrategia otomana de principios del siglo XVI eran evidentes ${ }^{3}$, lo cual condicionó el devenir de tales ocupaciones, siendo un frecuente impedimento al correcto desenvolvimiento de la vida de esas pobla-

\footnotetext{
1 SÁNCHEZ DONCEL, 1991.

${ }^{2}$ RICARD, 8 (41) (Paris, 1936a): 426; 79 (2) (Alger, 1936b): 687.

3 WOLF, 1979: 67.
} 
ciones, y a las directrices planteadas al inicio de la mencionada centuria ${ }^{4}$. No obstante, siempre constituyeron un eslabón en la cadena de información en el Mediterráneo ${ }^{5}$. Orán sería el enclave más importante en la costa argelina, pero los intentos por controlar otros espacios se sucedieron, aunque el éxito militar momentáneo apenas podía durar unos meses o pocos años, como ocurrió en Honein $^{6}$. En cierto modo, la ocupación geográfica indicada respondería al restablecimiento de una «marca de vigilancia por medio de ciudades fortificadas al otro lado de una frontera natural, como es el Mediterráneo»»7.

Esa vitalidad e impulso que se quiso dar desde un principio puede ser visto en la creación de una casa de contratación específica para Orán, aunque la vigencia fue efímera ${ }^{8}$. Su implantación perseguía minimizar los conflictos derivados de un comercio más allá del hinterland de la localidad, y armonizar el tráfico mercantil, en especial, con el litoral peninsular hispano, incluido en un sistema de intercambios que con el transcurso del siglo XVI y comienzos de la siguiente centuria vería la irrupción de nuevas potencias ${ }^{9}$. No obstante, los pleitos elevados a los tribunales competentes ponen de manifiesto que ni esa institución, ni la apelación a otros órganos de administración en la Monarquía española, pudieron hacer frente a los casos de personas imputadas por contrabando $\mathrm{u}$ otras desavenencias, estuviera o no vigente la jurisdicción de la citada institución. Esto ocurrió con Leonardo Espindola, mercader genovés, vecino de Granada, quien en nombre de un compañero suyo residente en la urbe oranesa, Francisco Hordan, se personaba en un pleito elevado a la Real Chancillería de Granada en 1548 «debido a lo proveido por el conde de Alcaudete, y por el corregidor y jueces de Orán, que tomaron sin causa çiertas caxas de perlas y aljofar y çinco pieças de Damasco, diziendo no averlas registrado» ${ }^{10}$.

Pese a las expectativas estratégicas, políticas y económicas abiertas tras la toma de Orán, en el plano de la población debía tener un marcado carácter militar, sin olvidar el constituirse en un destino de destierro para muchos reos acusados en los distintos tribunales de la Península. Un ejemplo sería el de Sebastián Caboto, denunciado por un capitán bajo su mando de haberse excedido en sus competencias, siendo condenado al pago de determinadas cantidades de dinero y, sobre todo, su envío a la ciudad oranesa para permanecer confinado dos años ${ }^{11}$. Privación de libertad que, en ocasiones, derivaba en

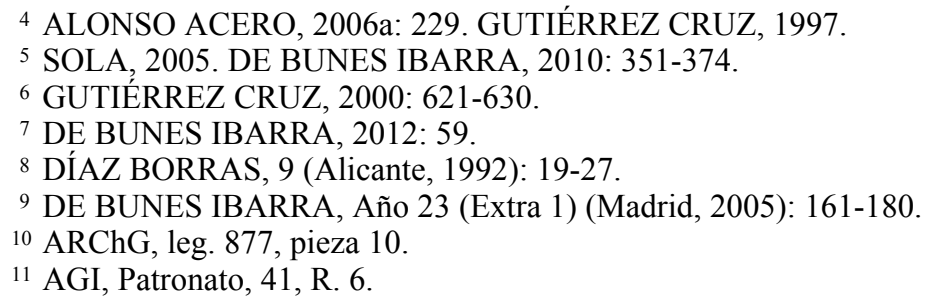


enfermedades que motivaban la intervención de familiares al objeto de conseguir levantar la pena impuesta, especialmente si el apoyo procedía de familias con influencia en sus lugares de origen. Esto ocurrió cuando en 1598 viene redactada una testificación relativa a la salud de Pedro Vique, destinado a Orán, intermediando sus hermanos don Álvaro Vique, gobernador de Orihuela, y don Juan Vique, obispo de Mallorca ${ }^{12}$.

Por nuestra parte, pretendemos contribuir al conocimiento de uno de los aspectos claves en la configuración de la población oranesa, como es la esclavitud. Pese a constituir un tema muy sugestivo para la historiografía modernista, referida al ámbito de la Península Ibérica ${ }^{13}$, todavía quedan por desgranar bastantes datos respecto a las posesiones hispanas en las orillas mediterráneas. Un mar Mediterráneo que, principalmente, desde la obra clásica de Fernand Braudel ${ }^{14}$, ha sido presentado como un escenario de contactos convulsos, en especial durante los siglos XVI y XVII, e integración en algunos $\operatorname{casos}^{15}$. El conflicto entre potencias, no siempre ajustado a las premisas de Cristiandad versus Islam ${ }^{16}$, ofrecía la posibilidad de capturar a personas para, posteriormente, venderlas o pedir un rescate por ellas ${ }^{17}$. Situaciones estas expuestas diariamente a la potencial abjuración de la religión primigenia ${ }^{18}$, con independencia del $\operatorname{sexo}^{19}$. Además, la plaza oranesa ofrecía un espacio de indudable importancia a la hora de obtener un pasaporte para la Península Ibérica, mediante el bautismo recibido y las connotaciones ligadas a él, o como estrategia de integración en el seno de la comunidad local. Los intereses económicos no serían cuestiones de menor relevancia en las posibilidades brindadas, a priori, con la utilización de tales estrategias.

Para completar el conocimiento sobre las cuestiones aludidas hemos consultado diferente documentación conservada en los archivos General de Indias, General de Simancas, Real Chancillería de Granada, Municipal de Málaga y, especialmente, en el Diocesano de Toledo. Además, recogemos ciertas noticias extractadas de la Biblioteca Nacional de España y de la Real Academia de la Historia.

Aunque los fondos parroquiales correspondientes a Orán han sido consultados por diversos autores, y recogido noticias insertas en sus volúmenes, todavía carecemos de un análisis sistemático de la información conservada.

12 AGI, Patronato, 270, n. 1, R. 23.

13 VINCENT, 2008: 39-64; 2011: 611-634.

14 BRAUDEL, 1949.

15 BONO, 2008.

${ }^{16}$ Una buena prueba de ello serían las alianzas puntuales de determinados reyes cristianos con los otomanos. ISOM-VERHAAREN, 2011.

${ }^{17}$ TARRUELL PELLEGRIN, 2014b: 293-310.

${ }^{18}$ MARTÍNEZ TORRES, 2004 y 2010: 27-47. FIUME, 2009.

${ }^{19}$ DURSTELER, 2011. 
Un primer intento de acercamiento al contenido de los mismos fue publicado en el año 2011, en el marco de una edición de investigaciones titulada Orán. Historia de la Corte Chica ${ }^{20}$. En aquella ocasión el periodo a examinar fue la década 1563-1572, con unas conclusiones que apuntaban a ciertas características propias del ámbito norteafricano bajo soberanía hispana, y con singularidades a concretar en los trabajos posteriores. En el presente artículo ampliamos el arco cronológico hasta final del siglo XVI, para estudiar la posible repercusión de determinadas acciones y acontecimientos llevados a cabo durante esas casi cuatro décadas de presencia española en la plaza oranesa, junto a la comparación pertinente, e ineludible, con los datos recogidos en otras investigaciones en curso de jurisdicciones cercanas o de características similares a las del enclave de Orán.

En 1563 Orán sufrió uno de los ataques y asedios que quedaron recogidos en la documentación y literatura de la época ${ }^{21}$. La difícil situación vivida es manifestada por el embajador español en Génova, Gómez Suárez de Figueroa, a través de varias misivas de junio y julio de ese año ${ }^{22}$, y la República genovesa en mayo ${ }^{23}$. Tales comunicaciones estaban en la línea de mantener informado al monarca hispano, no solo de los sucesos acaecidos, sino también de los previsibles movimientos de armadas en el Mediterráneo y de las posibles ofensivas sobre las plazas españolas, como ocurrió en $1564^{24}$. El mantener alerta el aparato bélico hispano alcanzaba las localidades del litoral peninsular, ante las eventuales incursiones dirigidas a realizar las habituales capturas de mercancías y personas, defender el territorio e imposibilitar o retrasar el embarque de suministros tan necesarios en los presidios norteafricanos ${ }^{25}$. Así lo hacía ver Juan Andrea Doria desde Málaga el 12 de julio de $1567^{26}$.

Por su parte, 1600 representa el primer bienio del reinado de Felipe III, final de un periodo de enfrentamientos con los enemigos cercanos y llegados a hostigar la plaza desde distintos puntos del Mediterráneo ${ }^{27}$, lo cual condicionaba el tráfico mercantil, incluido lo relativo a la esclavitud ${ }^{28}$.

${ }^{20}$ BRAVO CARO, 2011: 143-171.

${ }^{21}$ GAYTÁN, 1998.

22 AGS, Estado, leg. 1392, 32-33. Génova, 16 de junio y 18 de julio de 1563.

${ }^{23}$ AGS, Estado, leg. 1392, 82. Génova, 22 de mayo de 1563.

${ }^{24}$ AGS, Estado, leg. 1393, 32. Venecia, 28 de marzo de 1564.

${ }^{25}$ GUTIÉRREZ CRUZ, 24 (Málaga, 2012): 283-296.

${ }^{26}$ AGS, Estado, leg. 1396, 97.

${ }^{27}$ BRAH, 1/2669. Dialogo de las guerras de Oran, compuesto por el capitán Baltazar de Morales... 1593.

${ }^{28}$ MARTÍN CORRALES, 2001: 59-60. 


\section{LAS FUENTES PARROQUIALES DE LA VICARÍA ORANESA}

En esa fase final del quinientos, los principios tridentinos también se dejarían ver en los presidios. Al fin y al cabo, eran una prolongación del poder cristiano en los territorios bajo la soberanía del Islam. Las poblaciones asistirían a los intentos de acercamiento al mundo islámico con evidentes fines de evangelizar a la población de esa confesión ${ }^{29}$, sin desestimar los escasos pero significativos bautismos de judíos, grupo de secular asentamiento en el norte de África ${ }^{30}$.

El crisol de culturas, etnias o religiones tendría también su representatividad en una serie de comunidades dentro de las mismas sociedades, donde la frontera propiciaba no solo transgresiones a las normas formalmente establecidas y más observadas o reprimidas en la Península, con elementos de una singularidad manifiesta, sino grupos específicos de esos espacios, caso de los moros cristianos o rebatines ${ }^{31}$.

La posesión de personas esclavizadas formaba parte de la sociedad española de la Edad Moderna, independientemente del siglo o territorio que conformaba la Monarquía Hispánica, y su reflejo ha quedado visible en textos literarios $^{32} \mathrm{o}$ iconográficos ${ }^{33}$. En este sentido, los presidios norteafricanos no fueron una excepción. La propia legislación vigente recogía capítulos específicos sobre las distintas particularidades relacionadas con el estado de la esclavitud. Las mismas aportaciones dotales fijaban ciertos capítulos que debían quedar esclarecidos desde el ámbito del Derecho, y la oportuna descendencia del «bien» o persona esclavizada llevada al matrimonio tendría una consideración diferenciada en función de los avatares vitales de vida conyugal ${ }^{34}$.

Las incursiones, sobre todo cuando eran victoriosas, podían tener su reflejo en algunos géneros literarios del momento, donde era palpable el fin propagandístico y la exaltación de aquellas ocasiones que lograban derrotar al enemigo, con la obtención de un botín considerable ${ }^{35}$. Este tipo de interven-

${ }^{29}$ DE BUNES IBARRA, 16 (Pamplona, 2007): 157-167.

${ }^{30}$ EISENBETH, 96 (Alger, 1952): 114-187 y 343-384.

31 VARRIALE, 2013: 361-379.

32 GARCÍA BARRANCO, 2010: 151-171. MARTÍN CASARES, 2010: 173-188.

33 MÉNDEZ RODRÍGUEZ, 2012: 39-71; 2014: 33-54.

${ }^{34}$ Las siete Partidas del sabio Rey don Alfonso nono, nuevamente glosadas por el Licenciado Gregorio López del Consejo Real de Indias de su Majestad, Salamanca, Imp. Andrea de Portonaris, 1555. IV, Título XI, Ley XX.

${ }^{35} \mathrm{BRAH}, 9 / 3672(33)$. Relación muy verdadera, de dos presas y derrotas que en diferentes aduares de la Berbería en los confines de Orán, tuvo el señor Marques de Floredavila del Consejo de Guerra de su Magestad, y su Governador y Capitán general en aquellas partes. Donde se refiere la importancia destos sucesos. La muchedumbre de moros que quedaron muertos, que fueron tantos, que atajavan y ensangrentavan los ríos. El copioso numero de cautivos, bagajes, frutos y otras cosas de mucho precio que truxeron de la ciudad de Orán... 
ciones estaban alentadas porque servirían para intimidar a quienes no establecieran lazos de amistad con España. Así lo manifestaba por escrito Suárez de Montañés al referirse a la necesidad de llevarlas a cabo en el espacio oranés:

Y para que esos moros jeques, principales del reino, y sus súbditos, villanaje, así vengan de mejor gana a pedir seguro a los capitanes generales de Orán es necesario asimismo castigar y hacer presas ordinariamente en los demás que fueren de guerra, enemigos de aquellas plazas, para constreñirles y atemorizar a todos, y tratando bien a los amigos ${ }^{36}$.

Al margen de los beneficios obtenidos en las cabalgadas tampoco eran desdeñables los conflictos derivados del reparto posterior. Las problemáticas surgen desde el mismo inicio de la ocupación española de la zona de Mazalquivir y Orán, caso del pleito del almirante de Castilla con la mujer e hijos de Pedro Estopiñán ${ }^{37}$.

La vicaría oranesa quedó encuadrada en el arzobispado de Toledo ${ }^{38} \mathrm{y}$, por tanto, todas las directrices que en materia eclesiástica tuvieran su aplicación en el doble presidio de Mazalquivir-Orán debían ser ratificadas por aquella sede. Por otro lado, en lo referido al control de los fieles, el Tribunal del Santo Oficio tuvo una efímera existencia como institución autónoma respecto a otros peninsulares, para ser agregado definitivamente al de Murcia ${ }^{39}$.

En el plano que a nosotros nos interesa en este trabajo, uno de los corpus documentales más interesantes, al margen de los registros parroquiales, serán los capítulos referidos a la administración de los bautizos a celebrar en las parroquias de la ciudad norteafricana, en base a lo aprobado e inserto en las Constituciones Sinodales elaboradas a lo largo del siglo XVI en la urbe toledana. En concreto, la impresas en el año 1583, bajo el ministerio de don Gaspar de Quiroga, recoge nítidamente la obligatoriedad impuesta a los curas de la diócesis de contar con un libro donde asentarían los bautizos de cada una de sus circunscripciones, adquirido por el mayordomo de la iglesia correspondiente ${ }^{40}$.

Así pues, en consonancia con las directrices marcadas en el Concilio de Trento, la necesidad de recoger todos los acontecimientos llegaba también a

36 SUÁREZ MONTAÑÉS, 2005: 123-124. DE BUNES IBARRA, 2011: 323-368.

37 AGS, CRC, 5,2.

38 SÁNCHEZ DONCEL, 1991: 449-450.

${ }^{39}$ ALONSO ACERO, 55 (112) (Madrid, 2003a): 484.

40 Constituciones Sinodales hechas por el ilustrísimo y reverendísimo señor Don Gaspar de Quiroga, Cardenal de la Sancta Yglesia de Roma, del título de Sancta Balbina, Arçobispo de Toledo, Primado de las Españas, Chanciller mayor de Castilla, Inquisidor general en todos los Reynos y señorios de la Majestad del Rey Don Philippe nuestro Señor, y del su consejo de Estado..., con licencia, impresas en Madrid, en casa de Francisco Sánchez. Año de MDLXXXIII, fol. 7v. 
los enclaves norteafricanos. El valor de los libros resultantes es elevado, pese a las críticas que pudieran argumentarse en su contra. Al fin y al cabo, son los únicos documentos en los cuales las personas residentes en un lugar figurarían en algún instante de su trayectoria vital, ya fuera al poco de nacer, al formalizar un enlace matrimonial que le facultaría a mantener relaciones sexuales dentro de la legislación establecida — civil y eclesiástica-, o tras el fallecimiento. Cuando la información permite realizar el seguimiento de todas esas fases propicia unas conclusiones y análisis más completos. No obstante, para colectivos específicos como las minorías, y en particular las personas esclavizadas, el examen de determinados fondos parroquiales puede arrojar noticias directas e indirectas sobre prácticas sociales-religiosas, peso específico del grupo en el contexto de la comunidad, la evolución a lo largo de un periodo determinado, y las conversiones en dicha fase. Todo ello, convenientemente inserto en el marco de la sociedad y comparando los resultados con los obtenidos en otros núcleos de población.

En cuanto a lo que atañe estrictamente a los registros de bautismos de Orán conservados, y de los que tenemos constancia hasta el momento, se inician el día 12 de enero de 1563, año en que el rey de Argel realizó una «jornada» de la cual queda testimonio en ciertas relaciones del momento ${ }^{41}$. El rechazo de los enemigos fue acompañado de festejos en las capitales del litoral de la Península Ibérica, en una clara expresión de propaganda interna y exterior de una victoria frente al infiel ${ }^{42}$.

Poco antes de caer la plaza definitivamente en manos musulmanas, en $1792^{43}$, la documentación parroquial fue trasladada a Toledo, pero parte de la misma desapareció en el trayecto y durante los siglos posteriores. De hecho, la serie más completa corresponde a los bautismos, siendo nuestro estudio una muestra de lo conservado, cuyos resultados para los siglos XVII y XVIII están próximos a aparecer también en artículos de estas características. En el folio inicial del primer volumen queda constancia de ejemplares anteriores a la data indicada, y hace mención a la pérdida de las anotaciones desde 1509 . Igualmente, en 1676 el vicario de la feligresía oranesa certificó que ese año la parroquia tenía un tomo donde figuraban las personas bautizadas entre $1533 \mathrm{y}$ $1563^{44}$.

En líneas generales mantiene la estructura común a los fondos de esta naturaleza, sujeta a las reglas insertas en la documentación sinodal. La inobservancia de la norma era fiscalizada por la autoridad enviada desde la sede

${ }^{41}$ BNE, Mss. 18554/12. Relación de la jornada que hizo Hasán Bajá, rey de Argel, sobre las plazas de Mazalquivir y Orán, este presente año de 1563.

${ }^{42}$ AMM, Actas Capitulares, 16, fol. 203v.

${ }^{43}$ TERKI-HASSAINE, 2012: 188.

44 ADT, Orán, 3454, fol. 1r. 
episcopal, correspondiéndole a los visitadores que realizaban sus funciones periódicamente el dejar constancia por escrito en los libros inspeccionados de cualquier anomalía detectada. Una muy habitual era la falta de óleo y crisma, subsanado a la mayor celeridad posible, aunque a expensas de los suministros desembarcados o traídos por tierra a la localidad.

A la data le seguía el nombre de la persona que recibía el sacramento, la filiación y los padrinos o madrinas, los cuales figuran también con los vocablos «compadre» o «comadre». Esta estructura la aceptaban válida para todas las anotaciones, aunque las diferencias venían cuando los recién bautizados formaban parte del colectivo sometido a esclavitud, ya fuera hijo o no de esclava. En estos casos, la regla habitual observada en los registros parroquiales de las distintas parroquias españolas era escribir el nombre de la madre, que transmitía además el estado de sometimiento a su vástago. En muy contadas ocasiones figuraba el padre. Esta anomalía sin ser exclusiva de los colectivos marginados era más frecuente en ellos, aunque el ejemplo de Diego, bautizado por el beneficiado Diego de Vargas en 1563, no sería el único caso: «a un niño, hijo que dixeron que era de Diego López de Ángulo, regidor que en gloria sea... $\rangle^{45}$. A continuación podía recoger algún dato de interés para el cura o beneficiado encargado de oficiar la ceremonia: color de la piel, procedencia geográfica, étnica o religiosa, la tan aludida «nación» berberisca, mora o turca, o incluso de judíos, la edad aproximada, y el dueño o dueña. A la mención de los padrinos, le seguía la firma del oficiante. De igual manera, los libros encierran otras noticias, indirectas a veces y al margen de las estrictamente parroquiales, como la primera cabalgada del conde de Alcaudete en 1596, aunque la anotación viene al bautizar un niño capturado en ella: «...bapticé a Francisco, esclavo de el conde de Alcaudete, de edad de seys años, poco más o menos, y es de la cabalgada primera que hiço su señoría ${ }^{46}$.

En el plano de la cuantificación, el total de bautismos que los distintos curas o beneficiados dejaron recogidos en los volúmenes conservados, asciende a 3300. Unos 113 bautizos de media anual, en una población mediatizada por la fijación del contingente militar y civil desde el principio de la ocupación ${ }^{47}$. Las cifras fluctuarán a lo largo del quinientos, según las necesidades militares requieran mayor o menor guarnición destacada en el norte de África.

45 ADT, Orán, 3454, fol. 10v. Orán, 15 de agosto de 1563.

46 ADT, Orán, 3455, fol. 187v. Orán, 6 de noviembre de 1596.

${ }^{47}$ ALONSO ACERO, 2000: 74-91. 
TABLA 1. Bautizos celebrados en Orán (1563-1600)

\begin{tabular}{|r|r|r|r|r|r|r|r|r|r|r|r|r|r|}
\hline Año & ene & febr & mar & abr & may & jun & jul & ago & sep & oct & nov & dic & total \\
\hline 1563 & 4 & 2 & 11 & 6 & 3 & 7 & 11 & 12 & 7 & 7 & 5 & 16 & 91 \\
\hline 1564 & 11 & 7 & 9 & 10 & 7 & 8 & 8 & 6 & 8 & 4 & 8 & 8 & 94 \\
\hline 1565 & 12 & 14 & 8 & 14 & 4 & 4 & 8 & 9 & 13 & 8 & 8 & 11 & 113 \\
\hline 1566 & 11 & 5 & 10 & 12 & 8 & 3 & 4 & 3 & 5 & 7 & 11 & 8 & 87 \\
\hline 1567 & 8 & 9 & 7 & 5 & 4 & 7 & 8 & 12 & 2 & 5 & 0 & 5 & 72 \\
\hline 1568 & 13 & 6 & 8 & 8 & 9 & 4 & 5 & 11 & 4 & 8 & 11 & 9 & 96 \\
\hline 1569 & 4 & 4 & 14 & 7 & 8 & 6 & 12 & 5 & 7 & 1 & 11 & 10 & 89 \\
\hline 1570 & 7 & 3 & 11 & 5 & 6 & 9 & 11 & 1 & 0 & 0 & 0 & 0 & 53 \\
\hline 1571 & 8 & 12 & 3 & 3 & 11 & 5 & 11 & 2 & 9 & 9 & 13 & 10 & 96 \\
\hline 1572 & 18 & 11 & 17 & 14 & 11 & 2 & 9 & 4 & 3 & 6 & 12 & 10 & 117 \\
\hline 1573 & 15 & 4 & 12 & 9 & 9 & 6 & 9 & 10 & 8 & 18 & 8 & 12 & 120 \\
\hline 1574 & 15 & 10 & 7 & 6 & 4 & 6 & 8 & 10 & 8 & 10 & 10 & 8 & 102 \\
\hline 1575 & 12 & 6 & 1 & 5 & 2 & 5 & 12 & 7 & 3 & 5 & 5 & 8 & 71 \\
\hline 1576 & 9 & 5 & 4 & 15 & 7 & 3 & 4 & 13 & 12 & 8 & 5 & 10 & 95 \\
\hline 1577 & 9 & 8 & 7 & 0 & 0 & 7 & 2 & 0 & 0 & 0 & 0 & 0 & 33 \\
\hline 1578 & 0 & 0 & 0 & 0 & 0 & 11 & 0 & 0 & 0 & 0 & 2 & 5 & 18 \\
\hline 1579 & 15 & 0 & 0 & 0 & 0 & 0 & 0 & 0 & 0 & 0 & 0 & 0 & 15 \\
\hline 1580 & 0 & 0 & 0 & 2 & 7 & 11 & 0 & 0 & 10 & 4 & 0 & 0 & 34 \\
\hline 1581 & 0 & 0 & 0 & 0 & 0 & 0 & 0 & 0 & 0 & 0 & 0 & 0 & 0 \\
\hline 1582 & 0 & 0 & 0 & 0 & 0 & 0 & 0 & 0 & 0 & 0 & 0 & 0 & 0 \\
\hline 1583 & 0 & 0 & 0 & 0 & 0 & 0 & 0 & 0 & 0 & 0 & 0 & 0 & 0 \\
\hline 1584 & 0 & 0 & 0 & 0 & 0 & 0 & 0 & 0 & 0 & 0 & 0 & 0 & 0 \\
\hline 1585 & 0 & 0 & 0 & 0 & 0 & 0 & 0 & 0 & 0 & 0 & 0 & 0 & 0 \\
\hline 1586 & 0 & 0 & 0 & 0 & 0 & 0 & 0 & 0 & 0 & 0 & 0 & 0 & 0 \\
\hline 1587 & 0 & 0 & 0 & 0 & 0 & 0 & 0 & 0 & 0 & 0 & 0 & 0 & 0 \\
\hline 1588 & 0 & 0 & 0 & 0 & 0 & 0 & 0 & 0 & 0 & 0 & 0 & 0 & 0 \\
\hline 1589 & 15 & 9 & 6 & 7 & 9 & 13 & 10 & 10 & 6 & 15 & 9 & 9 & 118 \\
\hline 1590 & 15 & 8 & 16 & 19 & 7 & 9 & 6 & 8 & 5 & 12 & 14 & 12 & 131 \\
\hline 1591 & 8 & 18 & 15 & 10 & 5 & 3 & 8 & 17 & 10 & 12 & 12 & 17 & 135 \\
\hline 1592 & 19 & 11 & 15 & 11 & 11 & 10 & 17 & 14 & 22 & 10 & 10 & 12 & 162 \\
\hline 1593 & 25 & 14 & 18 & 13 & 12 & 7 & 8 & 11 & 14 & 12 & 12 & 17 & 163 \\
\hline 1594 & 7 & 12 & 12 & 16 & 9 & 13 & 18 & 18 & 15 & 12 & 13 & 11 & 156 \\
\hline 1595 & 20 & 15 & 27 & 8 & 14 & 6 & 19 & 9 & 11 & 19 & 11 & 16 & 175 \\
\hline
\end{tabular}




\begin{tabular}{|c|c|c|c|c|c|c|c|c|c|c|c|c|c|}
\hline Año & ene & febr & mar & abr & may & jun & jul & ago & sep & oct & nov & dic & total \\
\hline 1596 & 11 & 17 & 17 & 13 & 8 & 11 & 14 & 6 & 13 & 17 & 12 & 14 & 153 \\
\hline 1597 & 17 & 16 & 26 & 12 & 21 & 12 & 21 & 10 & 15 & 13 & 11 & 18 & 192 \\
\hline 1598 & 16 & 14 & 12 & 9 & 9 & 13 & 12 & 16 & 10 & 6 & 13 & 13 & 143 \\
\hline 1599 & 15 & 19 & 15 & 8 & 14 & 15 & 12 & 11 & 24 & 20 & 12 & 8 & 173 \\
\hline 1600 & 22 & 19 & 21 & 10 & 16 & 20 & 26 & 17 & 8 & 18 & 12 & 14 & 203 \\
\hline & 361 & 278 & 329 & 257 & 235 & 236 & 293 & 252 & 252 & 266 & 250 & 291 & 3300 \\
\hline
\end{tabular}

Fuente: ADT, Orán, 3454 y 3455.

El gráfico 1 que recoge la evolución de los bautismos efectuados en Orán refleja dos fases interrumpidas por el periodo 1581-1588, del cual no hemos encontrado anotaciones. Ello obedece también al incremento de efectivos que experimentará la guarnición en las dos décadas finales del siglo, motivado por el recrudecimiento de las acciones turcas en el Mediterráneo. Además, queda constatada la llegada de personas acompañando a miembros de la tropa o en busca de fortuna, sin necesidad de implicarse directa o continuamente en las actividades bélicas del enclave.

GRÁFICO 1. Bautismos celebrados en Orán (1563-1600)

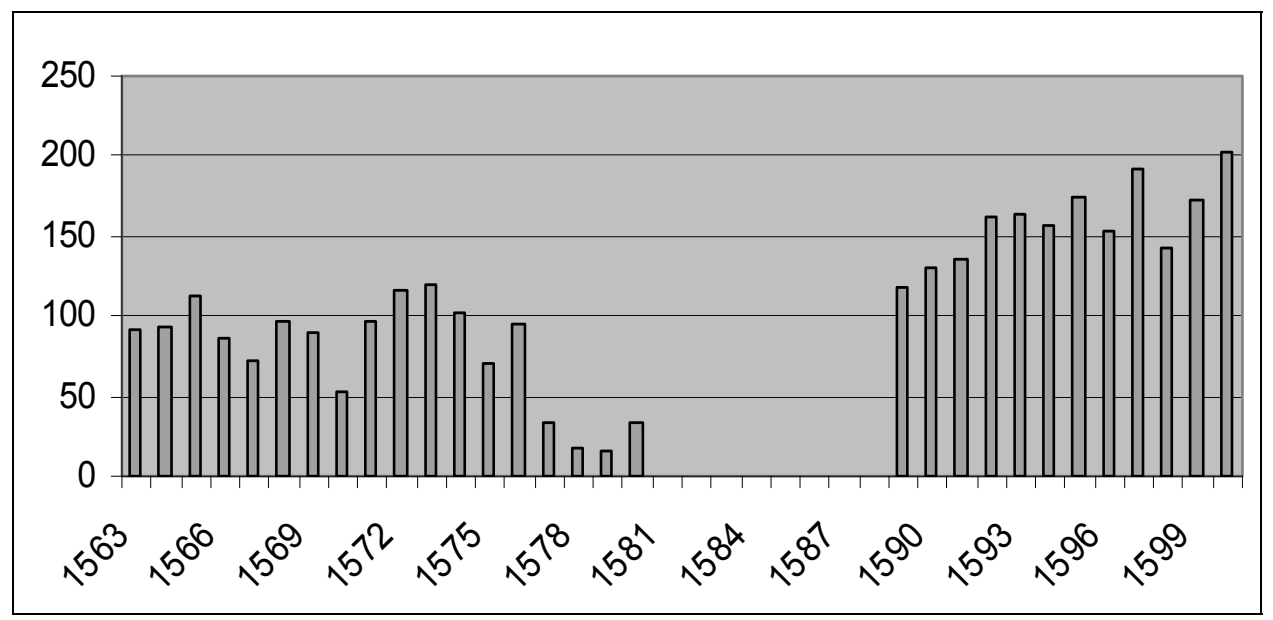

Respecto a la estacionalidad de las concepciones, en Orán jugarían otros factores al margen de los puramente reconocidos por los estudios de demo- 
grafía histórica. El crecimiento vegetativo de la población, pese a estar condicionado por cuestiones restrictivas en materia de respeto a los periodos de abstinencia sexual recogidos en la normativa confesional, y de aplicación en las circunscripciones diocesanas, o de los propios ciclos de explotación de la tierra, como han indicado determinados autores, en las plazas fronterizas norteafricanas también obedecieron al establecimiento de los contingentes militares, expuestos, a su vez, a las órdenes emanadas de Madrid. Por este motivo, las conclusiones que pudieran alcanzarse en este punto mantienen un margen de provisionalidad importante.

\section{EL BAUTISMO DE PERSONAS ESCLAVIZADAS (1563-1600)}

La propia complejidad de la sociedad oranesa y los múltiples intereses comerciales proyectados desde y hacia la urbe, sin olvidar su hinterland, confería un papel singular que repercutiría también en la adquisición de esclavos, distribución y posterior bautismo.

En ocasiones, los folios hacen referencia al desplazamiento posterior al bautizo, y la expresión «está en España» se repite en varios de ellos, lo cual asevera el flujo de esclavos que llegaba a la Península, muchas veces con el sacramento formalizado en su lugar de origen, coincidente con el núcleo de población de entrada formal en la fe de Cristo ${ }^{48}$.

Los libros correspondientes a las cuatro últimas décadas del siglo XVI recogen una cantidad global de 624 bautizos de personas esclavizadas, ya fueran adultas o hijos de esclavas, con una media anual de 21. Las anotaciones no difieren, en la base, de las correspondientes a las que no estaban sometidas legalmente a otras libres. Salvo en la referencia al progenitor, que en la inmensa mayoría no viene reflejada. También es de destacar el hecho, muy habitual, de señalar hijo o hija «de una esclava de...», por lo que la consideración social de la madre, ya de por sí inferior al del padre por ser mujer, es manifiestamente peor al no consignar no el apellido, prácticamente restringido a las féminas de familias acomodadas, sino siquiera el nombre de pila.

Al poner en comparación la evolución del total de bautizos celebrados en Orán con el de las referidas a las personas sometidas a esclavitud en el Gráfico 2, observamos cómo existe cierto paralelismo en las tendencias apreciadas. Sin embargo, en la década final de la centuria el incremento de las cifras generales no tiene una correlación, en cuanto a la magnitud, respecto al de esclavos. La explicación, al margen de un crecimiento demográfico auspiciado por la Corona, vendría también por el aumento del fenómeno de liberar al

${ }^{48}$ ADT, Orán, 3455, 31v. Orán, 8 de julio de 1590. 
esclavo antes del formalizar ritualmente su entrada en el catolicismo. Como es lógico, pese a su estado de sometimiento legal previo al bautismo, no queda contabilizado en el grupo de las personas esclavizadas, pues en el momento justo de recibir el agua bendita ya era liberto.

GRÁFICO 2. Comparativa entre el total de bautizos y de personas esclavizadas en Orán (1563-1600)

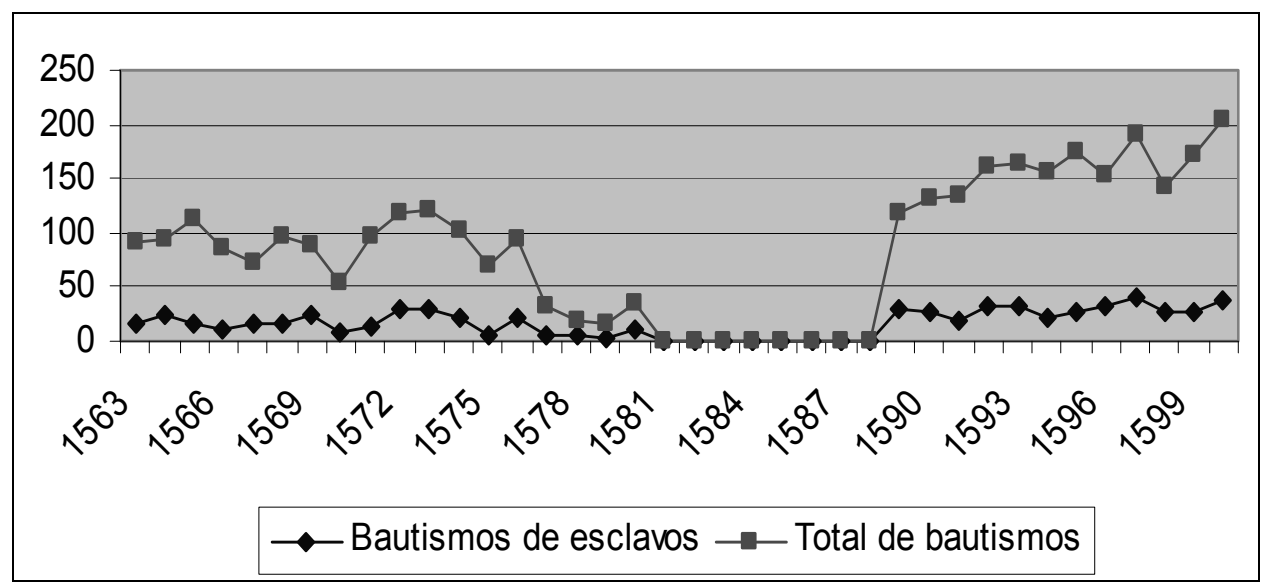

Fuente: ADT, Orán, 3454 y 3455.

Por otro lado, el hecho de recurrir a las cabalgadas como fórmula de castigo a las poblaciones vecinas y de obtención de botín en momentos de necesi$\mathrm{dad}^{49}$, también estará condicionado por el flujo de naves registrado en la ciudad oranesa, así como por el grado de inestabilidad política internacional en el Mediterráneo, junto a la no concreción de paces con los núcleos vecinos.

El porcentaje de bautismos de esclavos en relación con el total de la parroquia sería del $18^{\prime} 9 \%$. Tal cifra es muy elevada en comparación con la de otros puntos cercanos, también situados en la frontera frente al infiel, aunque con un carácter insular ${ }^{50}$. Ese carácter no peninsular de determinados territorios hispanos lleva a plantearse cierta invisibilidad de los musulmanes en el seno de las comunidades respectivas ${ }^{51}$.

La influencia de acontecimientos concretos operaba en la vía de incrementar el número de capturas y, posteriormente, de bautizos. Algo similar puede

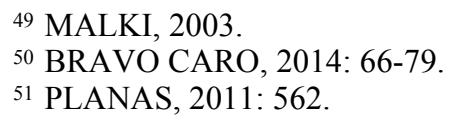


señalarse para Málaga, una ciudad de la costa peninsular donde la esclavitud estaba muy presente en la comunidad del quinientos y que en los años inmediatos a la jornada del emperador en Túnez (1535), conoció un crecimiento del número de bautismos de personas esclavizadas que rondaría el $40 \%$ en algunas de sus feligresías ${ }^{52}$.

Analizando más pormenorizadamente los datos podemos destacar que, en conjunto, el $62,98 \%$ son mujeres y el resto varones. Tal desproporción es indudable que responde a las características de una ciudad como Orán, lo cual no entra en contradicción con lo expuesto por muchos autores, en el sentido de considerar a la esclavitud como un fenómeno muy mediatizado por la presencia femenina. No obstante, la propia ubicación de la plaza es un condicionante, sin duda, de las cifras obtenidas. El enfrentamiento en el campo de batalla propiciaría la obtención del botín humano, pero las entradas en territorio enemigo en forma de cabalgadas registraría una mercancía en hombres inferior. De esta forma, se puede asegurar que las mismas fórmulas de captura influyen a la hora de conseguir «piezas» de uno u otro sexo.

Quienes figuran en los volúmenes consultados como hijas/os de esclava, representan el 31,89\% del total de personas esclavizadas, y un $6,03 \%$ del global de bautizos de la plaza, siendo muy superior la cifra de adultos o menores que no señalan tener progenitores sometidos a esclavitud, 68,10\% y $12,87 \%$, respectivamente en cuanto a las comparaciones establecidas. También en este punto el constituirse la ciudad en mercado de distribución y consumo de las personas cautivadas influye en las cantidades examinadas.

$\mathrm{Si}$ atendemos al sexo, diferenciando los dos grandes grupos planteados, podemos concluir que en el referido a los hijos de esclava el 57,28 \% son mujeres, mientras el resto figuran como varones. En el otro conjunto, el 65,64 \% viene representado por las féminas, y el $34,35 \%$ por los hombres. Por tanto, la desproporción en lo respectivo al sexo, aun considerando el mayor número de mujeres, es superior cuando nos fijamos en los porcentajes del segundo grupo.

Un análisis cualitativo de los datos incluidos en los libros de bautismos nos revela una información muy valiosa, en diversos aspectos. En cuanto la opción de poner un nombre a las personas esclavizadas, comprobamos la predilección de unos sobre otros $\mathrm{y}$, prácticamente, en casi ninguna ocasión coincide con el de la propietario o dueño del mismo. A veces es idéntico al de la madre y, por regla general, es simple, no lleva varios nombres, muy en consonancia con el conjunto de la población y la época, salvo el de determinadas familias de la élite militar o de la administración, tanto en el norte de África como en la Península. Algunas excepciones serían las de María Magdalena o Antonia María, y en los varones Francisco de Santo Domingo, y un tal Luis

52 BRAVO CARO, 1998: 439. 
de Aguilera une el apellido que, además, no es de su propietario, Alonso Álvarez de Fuensalida ${ }^{53}$.

Cuando nos detenemos en los nombres más usuales que les imponían, tendremos entre las mujeres el de María (17,15\%), Catalina (12,37\%), Ana $(11,59 \%)$ e Isabel $(9,53 \%)$. En los hombres los más habituales, Juan (34,64 $\%)$, Francisco (17,54 \%), Luis y Pedro (5,26 \%, respectivamente). Es decir, mantiene la tónica de lo cotidiano en otros puntos peninsulares.

Dadas las características de los emplazamientos, la mentalidad tan estricta de la Península sometida a los férreos controles de la Iglesia quedaba relegada a un segundo término. Los matrimonios de cristianos con conversos de judíos o musulmanes vislumbraban una realidad social muy particular en aquellos enclaves norteafricanos ${ }^{54}$. La situación llegó a plantear la posibilidad de enviar mujeres enamoradas para minimizar esos contactos sexuales con población autóctona de diferente confesionalidad ${ }^{55}$.

Los casamientos mixtos o entre personas esclavas ya estaban reconocidos en las Partidas, incluso los dueños debían favorecer la cercanía de los casados, hasta el punto de poder intervenir la Iglesia con la adquisición de uno de los dos esclavos si los propietarios les obligaban a vivir en localidades alejadas entre ellas, siempre con la condición fundamental de haber recibido el sacramento previo del bautismo ${ }^{56}$. Los mencionados matrimonios entre personas esclavizadas o los mixtos esclava/o-libre, fueron objeto de problemáticas habituales recogidas en la documentación judicial de los siglos XVI$\mathrm{XVIII}^{57}$.

En la documentación analizada los datos de progenitores de menores bautizados no llegan al $50 \%$ de los registros que señalan ser hijas/os de personas esclavizadas. Casi siempre figura la madre solamente, con su nombre en un porcentaje ligeramente superior al $41 \%$. Excepcionalmente refieren al padre, en cinco ocasiones. Un ejemplo de esto último sería el bautizo del esclavo Juan, hijo de Andrés de Berga y de Ana María, esclava de doña Luisa de Sotomayor ${ }^{58}$. Los enlaces tenían validez si ambos contrayentes eran conscientes, previamente, del estado servil de uno de ellos ${ }^{59}$.

${ }^{53}$ ADT, Orán, 3455, fol. 148r. Orán, 13 de marzo de 1595.

54 DE BUNES IBARRA, 1988: 579.

${ }^{55}$ BNE, Mss. 18554.

${ }^{56}$ Las siete Partidas del sabio Rey don Alfonso nono..., IV, Título V, Leyes I y II.

57 STELLA, 2000.

58 ADT, Orán, 3455, fol. 177v. Orán, 26 de marzo de 1596.

${ }^{59}$ Las siete Partidas del sabio Rey don Alfonso nono..., IV, Título II, Ley XI. «Servil condición es, la segunda cosa por que le embarga el casamiento. Onde sí algun ome que fuese libre casase con muger sierva o muger sierva con ome libre, no sabiendo que lo era, tal casamiento no valdría, fueras ende, si el libre consentiese en el otro de palabra, o de fecho después que lo sopiese, otorgado el casamiento ayuntándose a él carnalmente. Más si tal casamiento 
El no reflejar el padre de la criatura, y sólo recoger el nombre de la madre o una alusión al estado de privación de libertad de la misma, con términos de «hija de una esclava de», «hijo de una esclava cautiva de», «hijo de una esclava y de padres innotos», más allá de mostrar la escasa consideración social de los progenitores de los nacidos, nos plantea otras vías mucho más significativas. Por un lado, a nadie escapa que esos nacimientos eran fruto de encuentros sexuales de esclavas y sus dueños. Sin poder estimar cuantitativamente el alcance de estas acciones, su valor cualitativo sería elevado, máxime en una sociedad donde los contactos carnales al margen del matrimonio sufrían los castigos pertinentes contemplados en la normativa de la época. En segundo término, y vinculado estrechamente con lo anterior, tendríamos que el reflejo de los padres representaría un reconocimiento explícito de un sistema de relaciones interpersonales aceptadas, no prohibidas, pero tampoco recomendadas.

Al contemplar el color, evidentemente, pueden deducirse dos planos. Por un lado, el no favorecer los casamientos entre personas esclavizadas negras con blancas puede calificarse de prácticas claras de miscegenación. Incluso en el seno de cada uno de los grupos raciales aludidos, las diferencias en cuanto al origen religioso establecerían barreras difíciles de derribar. Es más, a partir de este punto podría llegarse a concretar ciertas actitudes que vislumbrarían una naturaleza de mixofobia.

No obstante, en Orán apreciamos que alrededor del $88 \%$ de las indicaciones a raza $u$ otra identificación étnica, se hacen refiriendo la presencia de fenotipos negroides, lo cual puede entrar en contradicción con lo apreciado en otros puntos de la metrópoli y para periodos anteriores, caso de Barcelona, donde una posible segmentación del grupo esclavizado arroja conclusiones del alcance que la sociedad de dicha urbe operaría los mecanismos pertinentes para garantizar la homogeneización «étnica» de la comunidad ${ }^{60}$. En línea con lo expuesto, pero de clara opción intergrupal, tendríamos lo constatado en puntos concretos de la Península Ibérica, como Granada, cuando puede apreciarse cierta propensión a formalizar uniones entre personas de idéntico co$\operatorname{lor}^{61}$. La localidad oranesa disfrutaba de una cercanía sin paliativos a la hora de acceder a las fuentes de aprovisionamiento, quizá con mayor diversidad. No obstante, hay que ser muy cautos cuando damos por sentado que los términos negro y musulmán van unidos. Pero sin existir referencias directas a tal asimilación deben distinguirse como colectivos en el seno del grupo esclavo, aunque en muchos casos las personas de rasgos negroides procedían del islamismo antes de ser bautizados.

como este fuese fecho, sabiendo el libre que el otro era siervo, ante que lo fiziese valdría el matrimonio, e no se podría por esta razon desfazer».

${ }^{60}$ PLAZOLLES GUILLÉN, 2000: 26-29.

${ }^{61}$ MARTÍN CASARES, 2000a: 363-364. 
Esta presencia negra en el colectivo esclavizado era heredera del tráfico de mercancías, incluidas las personas llegadas desde el centro del continente de manera regular, y mucho más habitual a partir de la superación de la barrera natural del desierto del Sáhara cuando la expansión árabe comenzó por esos espacios $^{62}$. La cifra de personas esclavizadas que transitarían por la ruta transahariana no sería inferior a los tres millones, y algunos la elevan hasta los cinco millones setecientos mil, con medias anuales de cuatro mil hombres y mujeres, en el periodo que iría desde el año 600 hasta el 149963. Muchas de aquellas personas, llevadas desde la banda sudanesa y del Atlántico hasta el Mar Rojo, se ocuparían de distintos quehaceres en el ámbito doméstico de sus dueños ${ }^{64}$. En el caso de los cristianos, también recogen las crónicas y la documentación de la época las entradas en Berbería para capturar negros que serían redistribuidos en los distintos mercados mediterráneos ${ }^{65}$.

En cuanto a la edad del bautizado, los datos examinados nos indican, en un porcentaje cercano al $40 \%$, los años aproximados que tendrían en el momento de recibir el sacramento. Ese número refleja el total de anotaciones, incluidos los hijos de esclava y el resto de personas de ese estado social. Las indicaciones van desde los 10 meses de edad hasta los 36 años, con mayoría de los comprendidos entre los 10 y 20 años. Además, algunas referencias más vagas nos hablan de «esclavica», «negrito» o «moza», de lo cual podemos deducir la corta edad de las mismas. En principio, de no consignar esos datos de los vástagos, cuando indican que son descendientes de una madre esclavizada, podemos concluir que son recién nacidos o con unos pocos días de vida. Sin embargo, no puede adoptarse como un axioma absoluto, pues el simple olvido a la hora de consignar el testimonio o la desidia de algún párroco evitaría una anotación correcta del acontecimiento.

En lo relativo al grupo de adultos, las Sinodales son muy explícitas, al indicar que debían ser suficientemente instruidos en la fe católica, conocer el idioma y solicitar el sacramento el propio interesado. El tiempo de catequesis mínimo estaría a discrecionalidad del sacerdote, «la qual mucho les encargamos, y mandamos a nuestro Iuezes que se informen si así no lo hazen, y castiguen a los transgresores» ${ }^{66}$. Es evidente que el cumplimiento de este punto, con todas las reticencias aceptadas, solo se materializaba en determinados casos de las conversiones voluntarias, casi siempre de personas libres o libertos, según veremos.

62 ENNAJI, 1999: 16-17. EL HAMEL, 2013, 113-132.

${ }^{63}$ MAUNY, 1970, 240-241. AUSTEN, 1979: 66. WRIGHT, 2007: 39.

${ }^{64}$ SEBAG, 1989: 53. QUENUM, 2008: 59-60.

${ }^{65}$ CORTÉS LÓPEZ, 1989: 43.

${ }^{66}$ Constituciones Sinodales hechas por el ilustrísimo y reverendísimo Señor Don Gaspar de Quiroga ..., fol. 6v. 
Los dueños de las personas esclavizadas que son bautizadas en la plaza oranesa presentan un perfil mayoritariamente masculino, pero con un nada desdeñable porcentaje algo superior al $10 \%$ de mujeres propietarias de esclavos. De estas últimas destacaría la condesa de Alcaudete, quien entre julio de 1596 y febrero de 1598 da el consentimiento para bautizar a 6 esclavas/os. Otras mujeres que anteceden a su nombre el «doña» característico de un reconocimiento social superior al de la mayoría de las féminas de la comunidad, figuran igualmente en calidad de dueñas. En el grupo de los hombres se constatan ciertos propietarios que ostentan la titularidad legal sobre un número más importante de esclavos, pese a que el poder participar en las cabalgadas y el acceso a unas almonedas relativamente cotidianas generalizan la posesión en el conjunto de los varones. No obstante, miembros de las diversas instituciones de Orán, ya sean civiles, militares o eclesiásticas quedan recogidos como personas que llevan a sus esclavos a recibir el sacramento bautismal.

Algunos de los esclavos bautizados en Orán procedían de las cabalgadas efectuadas en los días previos a la celebración del sacramento, o transcurrido un tiempo prudencial, lo cual contradecía la normativa sinodal referenciada. Ciertos sacerdotes de Orán, lejos de arrepentirse de tal actuación, la contemplaban como necesaria, pues el trágico final que podían tener en ocasiones, tras ser apresados los menores, era mitigado con la posibilidad de alcanzar el Paraíso al estar bautizados ${ }^{67}$. En este sentido, la transgresión a la ley de obligado cumplimiento a la hora de ser catequizado cualquier adulto antes de recibir el bautismo, era consentida hasta por el vicario o el cura que oficiaba la ceremonia.

Muchas veces, la penurias económicas sufridas por la tropa acuartelada, los retrasos en la llegada de los suministros enviados desde la península, o las deficitarias cosechas de los moros de paz circundantes fomentaban este tipo de incursiones cuyo fin era más la obtención de un botín seguro que el castigo militar al enemigo. Las desarrolladas en el periodo inmediatamente anterior a 1563 dan buena prueba de lo expuesto ${ }^{68}$.

Algunos de esos propietarios abandonarían la ciudad oranesa para instalarse en el litoral peninsular ibérico, pero sin descuidar sus actividades y contactos en tierras africanas, y participando de los intercambios mercantiles de Orán con el área murciana ${ }^{69}$. En concreto los registros de bautismos recogen diversas anotaciones referidas a Pedro Esteban de Mendiola, regidor en la urbe norteafricana y asentado en Cartagena a finales del siglo XVI, quien llevó a bautizar distintas esclavas en el periodo 1589-1597. La última de ellas fue

67 JIMÉNEZ DE GREGORIO, tomo XXII, n. LXXXV (Madrid, 1962), 110. «Allí compré dos niñas de teta y un niño y a los pocos días se fueron a gozar de Dios, y aunque perdí mi dinero, quedé muy contento por ver asegurada su salvación».

${ }^{68}$ MALKI, 2012: 164-166.

${ }^{69}$ MONTOJO MONTOJO Y RUIZ IBÁÑEZ, 120 (Murcia, 2009): 121-122. 
Isabel, de 6 años, y el propio Mendiola actuó en calidad de padrino junto a Petronila de Rosa, beata de Santo Domingo el Real, hija de Jaime Monterrey $^{70}$. La familia Mendiola tiene constatada su presencia en Orán con anterioridad a la documentación referenciada, pues otras fuentes los señalan en calidad de litigantes frente al concejo oranés, al ver lesionados sus intereses por los derechos inherentes a las posturas de la maquila que debían disfrutar los molineros de aquella urbe ${ }^{71}$.

Las altas autoridades militares de la plaza participaron activamente en el comercio de personas, y no son aislados los ejemplos de bautizos de esclavos en los registros parroquiales. Quien ostentara el cargo de capitán general de Orán en marzo de $1587^{72}$, don Pedro de Padilla, llevó a cristianar en 1589 a Francisco, negro de 20 años, asistiendo como testigos el mayordomo Antón de Larera y madrina la viuda Marta Rodríguez ${ }^{73}$. Igualmente, el conde de Alcaudete figura en varias anotaciones de los libros oraneses en calidad de dueño de personas esclavizadas que recibieron el agua bendita, en concreto tres entre noviembre de 1596 y septiembre del siguiente año: «bapticé a Ynes, esclava del conde de Alcaudete, capitán general y justiçia mayor por su magestad $\gg^{74}$.

El carácter estratégico de la plaza atrajo a comerciantes de diversos puntos del Mediterráneo, en consonancia a los contactos mercantiles y «naciones» establecidos desde la época musulmana en aquella zona. Los genoveses son uno de tales grupos ${ }^{75}$, y podemos constatar el bautismo de ciertos esclavos sujetos a la potestad de personas de ese origen. Así, el 9 de marzo de 1564 recibieron el sacramento bautismal Bárbara y Beatriz, de 25 y 4 años respectivamente, esclavas del mercader genovés Marco Antonio Conte ${ }^{76}$. Siete años después, Juan Bautista Grimaldo, de idéntica procedencia, llevaba el 30 de enero y el 10 de diciembre, ciertas moras a la pila bautismal ${ }^{77}$.

Igualmente, los responsables de las respectivas puertas que daban acceso a una ciudad de reconocida solidez en las fortificaciones levantadas durante décadas ${ }^{78}$, formaron parte del colectivo que poseía esclavos.

Quienes estaban sometidos a esclavitud no solo podían pertenecer a un particular, las instituciones también disfrutaron del servicio de algunas personas esclavizadas, siendo sus titulares legales. Así, en diciembre de 1596, reci-

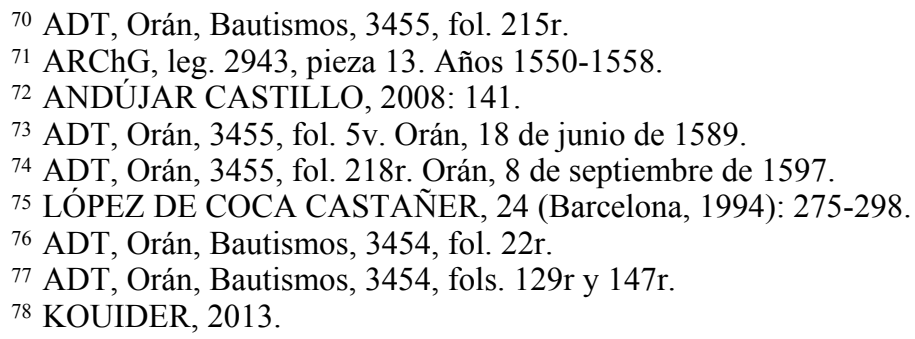


bió el bautizo Juan, esclavo entregado al convento de Santo Domingo, con la condición de no concederle la manumisión:

En beyntiseys días del mes de diciembre de mil y quinientos y noveynta y seys años, baptiçé a Juan, esclabo que era del beedor Juan de Castañeda, y se lo dio al conbento de Sancto Domingo el Real desta ciudad de Orán, y que no pudiese ser bendido, de edad de seys años, poco más o menos, fue su padrino el capitán Gil Hernández de Sotomayor, y la madrina su muger doña Beatriz de Sotomayor, muger del dicho ${ }^{79}$.

El colectivo hebreo residente en Orán también tuvo una participación activa en el mercado de esclavos, y así se deriva de algunos bautismos registrados en la parroquia. En concreto Juan y Francisco de Santo Domingo, recibieron el sacramento en septiembre de 1571 y agosto del siguiente año respectivamente, siendo su dueño un judío llamado Cansino ${ }^{80}$. Miembros de esta familia continúan figurando como poseedores de esclavos en distintas décadas del siglo $\mathrm{XVII}^{81}$, y alguno de ellos, caso de Jacob Cansino, compatibilizó hasta al día de su fallecimiento sus actividades con las de intérprete, siempre tan necesario en un núcleo urbano de tales características ${ }^{82}$. Hasta su expulsión de $1669^{83}$, acontecimiento inserto en varias relaciones ${ }^{84}$, la comunidad judía formó parte del crisol humano de la localidad, pese a la desconfianza de los cristianos viejos ${ }^{85}$, y destacaron en las facetas económicas atribuidas secularmente al grupo social en cuestión ${ }^{86}$. El abandono del territorio español sólo supuso un paréntesis en su presencia como vecinos activos de ese espacio norteafricano $y$, al igual que ocurriera con sus antepasados castellanos en la Península Ibérica, volverían tiempo después, conformando un porcentaje nada desdeñable de la población una vez abandonada la plaza por los españoles ${ }^{87}$.

Las referencias a quienes asistían en calidad de padrinos siempre figuran en la documentación. Aparecen mencionados como compadre, padrino, comadre o madrina. Por regla general es un hombre y una mujer, pero ciertas anotaciones recogen el doble, comprobando las similitudes con el resto de la

79 ADT, Orán, 3455, fol. 194v. Orán, 26 de diciembre de 1596.

80 ADT, Orán, Bautismos, 3454, fols. $158 \mathrm{v}$ (7 de septiembre de 1571$)$ y 169v (7 de agosto de 1572).

${ }^{81}$ VINCENT, 2003: 248-251.

82 DÍAZ ESTEBAN, 11 (Madrid, 2000): 257.

${ }^{83}$ SÁNCHEZ BELÉN, 6 (Madrid, 1993): 155-197. SCHAUB, 1999. PULIDO SERRANO, 2003: 201-222.

${ }^{84} \mathrm{BRAH}, 9 / 3606(8)$. Breve relacion y compendioso epitome de la general expulsión de los hebreos de la iuderia de la ciudad de Orán devida al católico zelo...

${ }^{85}$ ALONSO ACERO, 2003b: 223-243.

${ }^{86}$ MARTÍN CORRALES, 2003: 251-281.

${ }^{87}$ SALINAS, 2004: 121. 
población. En principio, la función e importancia de dichas figuras es básica a la hora de formalizar el ingreso del catecúmeno en el catolicismo. En lo que respecta a los esclavos, tampoco es habitual que el dueño o propietaria figure como padrino o madrina. Si las personas esclavizadas son de algún oficial o familia relevante de la ciudad, en ocasiones queda atestiguada la participación de individuos de similar categorización social, aunque el conjunto de casos es mínimo. Ejemplo lo tendríamos en el bautizo de Ana «esclavica mora» de 10 años, cuando el genovés Juan Bautista Grimaldo figura en ambos cometidos ${ }^{88}$.

A destacar es igualmente la participación en calidad de padrinos de algunas personas de procedencia geográfica común. Las referencias a los originarios del espacio italiano son manifiestas y tenemos al milanés Petolo Nicolao apadrinando, junto al mercader Gaspar Martín, a dos esclavas del genovés mencionado más arriba, Marco Antonio Conte en marzo de 1564.

Habitualmente, cuando era celebrado un bautizo de dos personas esclavizadas los padrinos coincidían, pero podía suceder que cada una tuviera los suyos. En el celebrado en marzo de 1597, para dos esclavas de la condesa de Alcaudete, ocurre esto, lo cual, dada la relevancia social de algunos de sus integrantes se trataría de un formalismo más acorde con prácticas de mantenimiento y pertenencia a relaciones sociales de dichos padrinos y madrinas con la dueña de las bautizadas, que de un compromiso firme de lo inherente a la vinculación establecida ente bautizado y padrinos:

bapticé a Benita y Agustina, esclabas de la condesa de Alcaudete, de edad de onçe años, Benita y Agustina de catorçe años, poco más o menos, fueron sus padrinos Gerónimo de Angulo, mayordomo del conde, y doña Beatriz de Cárdenas y Parias, la madrina [¿?] de Benita, y Andrés Hernández, alguacil mayor, y doña Elbira de Albarado, de Agustina, negra ${ }^{89}$.

\section{CONVERSIONES}

Al igual que el fenómeno de los renegados cristianos plantea una difícil respuesta ${ }^{90}$, en cuanto a las causas que estarían detrás de dichas abjuraciones y las motivaciones inherentes a una decisión de ese calado ${ }^{91}$, en el plano inverso no son menos problemáticas. Incluso, las fuentes son más escasas o parcas a la hora de mostrarnos la diversidad de opciones.

Cuestión de menos repercusión historiográfica, las conversiones al catolicismo han despertado, sin embargo, un mayor interés en la última década.

\footnotetext{
${ }^{88}$ ADT, Orán, Bautismos, 3454, fol. 129r.

${ }^{89}$ ADT, Orán, 3455, fol. 204r. Orán, 21 de marzo de 1597.

90 DE BUNES IBARRA, vol. 42, 85 (Madrid, 1990): 181-198.

${ }^{91}$ BENNASSAR y BENNASSAR, 1989: 349-368.
} 
Empiezan a ser más numerosos los trabajos que abordan el análisis de casos particulares ${ }^{92}$, o de las características generales observadas en determinada documentación ${ }^{93}$.

Las prácticas de las conversiones se registran desde la misma incorporación del último bastión islámico a la Corona de Castilla ${ }^{94}$. Ese carácter de frontera que representaban las jurisdicciones nazaríes revestirá similitudes respecto a otros espacios del norte de África caso de Orán, donde no era excepcional la conversión de personas o familiares de personajes relevantes de las respectivas comunidades ${ }^{95}$.

Las Sinodales también recogían algunos puntos de honda trascendencia a la hora de contemplar la llegada de nuevos cristianos desde el resto de religiones. Como se vio más arriba, la Iglesia mostraba una especial atención en la catequización de aquellas personas adultas que quisieran optar por ese camino. En este sentido, algunos miembros de determinadas órdenes religiosas expresaron la necesidad de acometer las labores evangelizadoras de forma mucho menos traumática que las llevadas a cabo hasta ese momento ${ }^{96}$. Un aspecto fundamental era la voluntariedad de tal iniciativa, y el cura responsable de dar el visto bueno a la preparación de catecúmeno certificaría el grado de conocimiento de los preceptos básicos, además de las razones que le impulsaron a dar ese paso tan decisivo ${ }^{97}$.

Una de las conversiones de mayor relevancia, efectuada durante el periodo tratado aquí, fue la de don Felipe de África, quien tras huir de la zona marroquí fue bautizado en Madrid a finales del siglo XVI ${ }^{98}$. Algunos ejemplos más incrementan la nómina de los recién llegados a la fe de Cristo, procedentes del Islam, y con intercesión de prelados y autoridades eclesiásticas o civiles en la España de la época ${ }^{99}$. La plaza oranesa no será ajena a este fenómeno, constatándose un episodio digno de ser recogido en la literatura, por las implicaciones y el alcance que tuvo hasta en la corte de Madrid, con interrogatorios y causas abiertas por supuesta suplantación de identidad de Mahamete ben Muley Nazar ${ }^{100}$.

A diferencia de la Península Ibérica, donde la obligatoriedad de ser cristianos para poder permanecer en sus seculares lugares de asentamiento había

92 TARRUELL PELLEGRIN, 2011: 263-288. GARCÍA-ARENAL, 2013: 35-60 .

93 BONO, 1998: 429-446. VINCENT, 2001: 193-205; 7 (1) (Brescia, 2010): 61-70; 2011: 611-634.

94 DE BUNES IBARRA, 2008: 99-116. ECHEVARRÍA ARSUAGA, 2001: 119-138.

${ }^{95}$ LÓPEZ DE COCA CASTAÑER, 39 (Sevilla, 2012): 129-151.

${ }^{96}$ FIUME, 7 (1) (Brescia, 2010): 35-60.

${ }_{97}$ Constituciones Sinodales hechas por el ilustrísimo y reverendísimo Señor Don Gaspar de Quiroga ..., fol. 6r-v.

${ }^{98}$ OLIVER ASÍN, 2008.

99 TARRUELL PELLEGRIN, 2014a: 263-271.

100 ALONSO ACERO, 2006b: 98-103. 
llevado desde principios del siglo XVI a miles de personas a bautizarse ${ }^{101}$, en los presidios norteafricanos la realidad sería diferente. Puede afirmarse que, sin llegar a un reduccionismo excesivo del planteamiento, las personas que optaban por recibir ese primer sacramento, y lo decidían libremente sin estar sometidos a esclavitud y, por tanto, a la decisión de sus dueños, buscaba otro tipo de beneficio, no siempre de carácter espiritual. En cierto modo, el bautismo facilitaba un pasaporte para la Península, aunque la celosa mirada de la Inquisición fijaría sobre ellos una atención bastante más incisiva en comparación al resto de colectivos existentes. Los principios de taqiyya o niyya ${ }^{102}$ responderían en Orán y, por extensión, en los demás presidios hispanos en África a planteamientos y resoluciones diferentes a los operados por las comunidades moriscas de Castilla y Aragón, incluso teniendo en cuenta el origen oranés de uno de los muftí de mayor influencia en los neoconversos peninsulares durante los reinados de los denominados Austrias mayores ${ }^{103}$. Los procesos inquisitoriales ponen de manifiesto la actividad del Tribunal a la hora de perseguir los comportamientos heterodoxos, incluidas las personas esclavizadas ${ }^{104}$.

La trascendencia de estas conversiones se enmarcaba en el contexto de victorias en la lucha contra el Islam, al igual que el contingente de renegados cristianos representaba la cara inversa de la moneda en el enfrentamiento secular de las dos religiones, que trascendía el espacio geográfico para elevarse al espiritual. Los instrumentos de difusión eran múltiples ${ }^{105}$, sin desdeñar el vehículo de la literatura que, pese a desarrollarse en sociedades con un alto grado de analfabetismo, el mensaje último llegaba a gran parte de los rincones de las diferentes comarcas hispanas ${ }^{106}$. Aunque las registradas en Orán no obtendrían el reconocimiento escrito dentro de las líneas propagandísticas desplegadas en los siglos XVI o XVII ${ }^{107}$, cuando algún personaje otomano o berberisco de importancia en su comunidad de origen abrazaba la fe de Cristo ${ }^{108}$. Sin embargo, en los delicados límites fronterizos norteafricanos alcanzaban una gran significación. Pero en honor a la verdad, no fueron extraordinarias las casuísticas de conversión, apostasía y vuelta al cristianismo de

${ }^{101}$ GARCÍA-ARENAL y RODRÍGUEZ MEDIANO, 2011: 23. POUTRIN, 2012.

102 BERNABÉ PONS, 34 (2) (Madrid, 2013): 519-521.

103 STEWART, 27 (2) (Madrid, 2006): 265-301.

104 ALONSO ACERO, 50 (101) (Madrid, 1998): 101-132; 55 (112) (Madrid, 2003a): 492-493.

${ }^{105}$ RODRÍGUEZ MEDIANO, 2013: 537-563.

106 ROMANOS, 2001: 1145-1150. PESTRE DE ALMEIDA, 8 (Torino, 2012): 35-49.

107 SANZ HERMIDA, 2008; 287-298. CARABIAS TORRES, 20 (Madrid, 2010/1).

$108 \mathrm{BNE}, 3 / 72179$. Breve relación de mi origen, con diversas atestaciones de mi persona, autenticadas en toda forma cuyos originales conservo y otra sucinta relación de las persecuciones sucedidas a mí Don Juan Miguel Otomano Cigala después que Dios nuestro Señor por su infinita Misericordia me iluminó a la Santa fe católica, s.n., ¿1663? 
algunas personas de origen musulmán que, al marcharse poco tiempo después de ser bautizadas, renegaban al huir hacia tierras bajo dominio del Islam, para regresar a la ciudad oranesa ${ }^{109}$. La solicitud de una segunda oportunidad en la fe de Cristo revestía mayor complejidad si cabe, pues las acusaciones se multiplicaban dado el origen y la naturaleza de apostasía, además del territorio donde era llevado a cabo.

Tales conversiones de musulmanes al cristianismo no eran privativas de las jurisdicciones ribereñas del Mediterráneo, apreciándose idénticos procedimientos de cambio confesional en territorios mucho más alejados, por ejemplo, en las Islas Británicas ${ }^{110}$, aunque la proporción o representatividad de unos y otros diferiría. Al fin y al cabo, de lo que se trataba era de poder integrarse, regularizar su presencia o simplemente evitar discriminaciones, al menos a priori, en cualquier jurisdicción europea de asentamiento para aquella población de origen musulmán, desde las tradicionales comarcas andaluzas hasta los más recónditos rincones del continente ${ }^{111}$.

En el caso de los judíos que solicitaban el bautismo, una serie de normas y decretos dictados en determinados años del siglo XVI, por parte de la máxima institución del catolicismo, pretendía regularizar una situación de tanta significación como la llegada al seno de la Iglesia de personas que habían seguido las directrices judaicas durante generaciones ${ }^{112}$. Esta problemática no era exclusiva de los territorios bajo soberanía española, pues en la propia Roma pudieron apreciarse las casuísticas presentadas por quienes abjuraban de su antigua creencia ${ }^{113}$.

En cuanto a la conversión al cristianismo de los heterogéneos grupos étnicos o de religiones diversas, la Iglesia católica también tuvo distintas pautas de actuación ${ }^{114}$. Especial atención ponían en los neófitos llegados del Islam, no solo en la Península Ibérica, enmarcados en el proceso de aculturación emprendido tras la incorporación a Castilla del reino nazarí, sino también en la franja norteafricana. Igualmente, las personas negras planteaban una problemática particular, pues no siempre podía establecerse la relación negromusulmán, y su entrada en la fe de Cristo suponía una especificidad concreta. De hecho, la población africana que fue incluida en la trata atlántica recibía el bautismo en momentos diferentes, antes de embarcar o en tierras americanas, e incluso no aplicaban la obligatoriedad del bautismo en lo que algunos auto-

109 ALONSO ACERO, 2012: 80.

110 DAKHLIA, 2013: 161-187.

111 STELLA, 2000: 175-189; 2011: 457-469. LAHON, 2000: 275-311. MARTÍN CASARES, 2000b: 207-221. VALENSI, 2012. TARRUELL PELLEGRIN, 2013: 545-554.

112 PARENTE, 51 (1) (Madrid, 1991): 339-352.

${ }^{113}$ CAFFIERO, 123 (3) (Bologna, 2007): 819-839; 2011: 593-609.

114 BRAVO CARO, (en prensa). 
res han considerado una estrategia para preservar cierta pureza de sangre ${ }^{115}$. Práctica ésta que no era nueva en el ámbito de dominio islámico, al fundamentarse en algunos territorios del continente durante la época medieval y principios de la moderna. En efecto, las dificultades económicas junto a la repercusión de los embates epidémicos padecidos en el litoral marroquí de las décadas iniciales del quinientos influyeron notablemente en el movimiento de conversiones al cristianismo ${ }^{116}$. Algunas investigaciones hablan de varios miles de personas, algo sorprendente dado el grado de hostilidad de los reinos bajo ambas religiones ${ }^{117}$.

Evidentemente, estas victorias incruentas contrastaban con esa otra visión alimentada durante siglos, también recurrida en el XVI, de la figura del Santiago Matamoros triunfante frente a los musulmanes ${ }^{118}$. Pero además de las conversiones con más huella, por la figura de quien se trataba, algunas madres planteaban la opción de abrazar la fe de Cristo junto a su hijo ${ }^{119}$. Otras veces, se menciona que la progenitora era esclava pero en el momento del bautizo tanto ella como su hija alcanzaron la libertad. También la condición de esclava de la madre permanecía en ella al ser manumitido su hijo en el instante previo a recibir el sacramento. En otras ocasiones, pese a ser apresada en las cabalgadas indicadas, se daba la circunstancia de entregar a una familia la menor capturada, al objeto de ser criada en las religión católica ${ }^{120}$.

Respecto a las conversiones de judíos, aunque no fueron tan numerosas como en el caso de los musulmanes, algunas se produjeron en el Orán de las cuatro décadas finales del siglo XVI. Algo similar acaeció en la zona marroquí durante toda esa centuria, motivada por las dificultades económicas y la presión soportada ${ }^{121}$. Como ya expusimos anteriormente, esta era la otra cara de la moneda en la actividad proselitista de las religiones en el continente africano, pues los judíos también desplegaron estrategias para convertir a sus esclavos domésticos ${ }^{122}$.

Junto a esas conversiones de judíos también se produjeron bautismos de personas esclavizadas bajo el dominio legal de miembros de esa comunidad

115 QUENUM, 2008: 102-104.

116 BOUCHAREB, 1988: 497-498 y 507.

117 ROSENBERGER, 1988: 621.

118 FÉRNANDEZ GALLARDO, 15 (Madrid, 2005): 139-174. MOORE, 36 (2) (Columbus, 2008): 313-344. CABRILLANA CIÉZAR, 1999.

${ }^{119}$ ADT, Orán, 3455, fol. 117v. Orán, 24 de abril de 1594. «Baptizé a Diego, hijo de Jacob Cansino, catecumino que quiere ser cristiano y de una mora que quiere ser cristiana, fue su padrino el sarjento mayor Gaspar Prieto, y la comadre Madalena Justiniano, hija de Fabriçio Justiniano, difunto».

${ }^{120}$ ADT, Orán, 3455, fol. 100r. Orán, 16 de agosto de 1593.

${ }^{121}$ BOUCHAREB, 1988: 515.

122 LEWIS, 1990: 8-9. 
judaica, lo cual habla de las diferentes prácticas y realidades en un núcleo de población tan singular como Orán. En cierto modo, el proselitismo de ciertos grupos no operó de igual manera, quizá porque existieran filtros de aceptación, ya expuestos, y que seguirían operando en el sistema de relaciones imperantes en la localidad oranesa. Por encima de otros resalta el bautizo de Juan, «de nasión árabe, cautivo que fue de tres judíos, y baptisando se queda y consige libertad» ${ }^{123}$.

Tampoco dejaremos de mencionar la casuísticas de aquellas personas llegadas a Orán en calidad de rehén, a la espera de llegar a acuerdos entre particulares por deudas o intercambios de esclavos y que, al transcurrir el tiempo, optaron por abandonar sus antiguas creencias para hacerse cristianos. Ejemplo de esta situación sería: «Ana, esclava que hera de Benito Diez, cabo desquadra, y bino en reén, y es libre» ${ }^{124}$.

Tras el pago de la deuda contraída algunas personas decidían renunciar al Islam y hacerse católicos ${ }^{125}$. Otras veces, el deseo de cambiar de religión suponía un verdadero problema, incluso de índole comarcal por las implicaciones de la familia musulmana, reacia a que alguien de la unidad doméstica se desplazara hasta Orán para hacerse cristiano ${ }^{126}$.

La documentación también recoge la práctica de, en un mismo acto, bautizar a personas esclavas y horras, con la participación de los mismos padrinos en el evento:

baptizé a María de edad de treinta años, poco más o menos, y una hija suya de edad de quatro años, poco más o menos, llamada Christina, y son horas, madre y hija, y una niña que truxeron de una cabalgada y es esclaba llamada Catalina de edad de un año, poco más o menos, y es del alcalde mayor Pedro Martínez de los Rios, fueron padrinos de todos tres, el regidor Pedro Esteban Pérez de Mendiola, y la madrina doña Ysabel, y fueron Ana María Pérez de Mendiola127.

La liberación podía llevar la condición de mantenerse durante un tiempo al servicio de alguien, para cumplida la edad estipulada, alcanzar la libertad. Esto le ocurrió a María, en diciembre de 1596, capturada previamente «junto a Amostagan, y el señor conde de Alcaudete le mandó dar libertad con condición que sirviese a Sebastián Rodríguez, y a su muger Mari Hurtada asta de edad de diciseys años, y entonces yciese de su persona a su boluntad» ${ }^{128}$.

${ }^{123}$ ADT, Orán, 3455, fol. 155r. Orán, 28 de mayo de 1595.

${ }_{124}$ ADT, Orán, 3455, fol. 150v. Orán, 28 de marzo de 1595.

${ }^{125}$ ADT, Orán, 3455, fol. 295r. Orán, 6 de agosto de 1600.

${ }^{126}$ ADT, Orán, 3454, fols. 63v-64r. Orán, 3 de diciembre de 1565. BRAVO CARO, 2011: 156-157.

127 ADT, Orán, 3455, fol. 175r. Orán, 1 de marzo de 1596.

128 ADT, Orán, 3455, fol. 194r. Orán, 13 de diciembre de 1596. 


\section{CONCLUSIONES}

En definitiva, en lo que respecta al fenómeno de la esclavitud la ubicación de Orán como frontera frente al enemigo norteafricano, allí en su continente, y las características de los bautismos celebrados y analizados para el periodo 1563-1600, propician unas singularidades propias, pese a que las podríamos encuadrar en el general devenir de lo reseñado para el Mediterráneo. Sin embargo, su carácter de emplazamiento, en la frontera en sí, pero en un territorio dominado por el adversario, le confería una singularidad respecto a lo apreciado en otros puntos, también estratégicamente importantes y hostigados por turcos o berberiscos, caso de Cagliari ${ }^{129}$.

Aun siendo conscientes de la naturaleza de las fuentes examinadas, no es menos cierto que los resultados obtenidos constituyen unas teselas más del mosaico final. Además, nos indican prácticas concretas de fenómenos como la conversión voluntaria o no, aunque en principio todas debían serlo. En verdad, las motivaciones para cambiar de religión obedecerían a una casuística muy variada, en la cual no debe descartarse ningún tipo de planteamiento personal. Evidentemente, pese a las similitudes que algunos autores han querido ver en las conversiones llevadas a cabo en el ámbito musulmán desde el paganismo, al menos en el colectivo de personas negras, no es aplicable. La opción de recuperar la libertad perdida en las incursiones estaba aceptada con reticencias, según las jurisdicciones bajo dominio islámico, aunque extendido por la mayoría de los territorios. Este factor de obtener la manumisión operaría como un elemento básico cuando tales esclavos negros abandonaran sus creencias y formalizaran el paso a la nueva religión musulmana, sobre todo si tenemos en cuenta que, para ellos, no existía la posibilidad de un rescate próximo o dilatado en el tiempo como en los cristianos, y su permanencia en cautividad podría extenderse hasta su fallecimiento, salvo la liberación por parte de su dueño ${ }^{130}$.

Podríamos hablar de modelos, incluso dentro de los tradicionales mediterráneo y atlántico, pues las investigaciones realizadas y los trabajos en curso invitan a parcelar ese gran planteamiento de la esclavitud en las orillas del Mediterráneo. El mercado oranés se beneficiaría de esa posición privilegiada en la frontera, pues la propia ciudad era frontera, y la llegada de personas esclavizadas a partir de las cabalgadas no necesitaba del flujo comercial de otras ciudades en la Península. La mercancía estaba en las mismas puertas de la urbe y, pese a las múltiples reclamaciones de los integrantes por unos derechos que veían lesionados muy habitualmente en cualquier plaza norteafrica-

${ }^{129}$ BRAVO CARO, 2014: 66-79.

130 SEBAG, 1989: 144-146. 
na ${ }^{131}$, el negocio era floreciente, en la esfera particular y de la Corona. Por esta razón, las autoridades se esforzaban en reglamentar todo lo relativo a esas entradas en territorio enemigo ${ }^{132}$. Los acontecimientos que tanto influyeron en la recepción de esclavos desde los puntos de conflicto, como ocurrió en Málaga en 1535, complementaban unas ventas más habituales en la plaza oranesa.

El recurso a liberar a menores apresados en las cabalgadas efectuadas fue habitual durante la última década del quinientos. El número de libertos por esta fórmula, sin ser excesivo si lo comparamos con los bautizados que son esclavos capturados en las mismas circunstancias, es digno de reseñar como práctica llevada a cabo.

Por último, los fondos parroquiales confirman informaciones obtenidas en otras fuentes, como las notariales, al indicarnos que una persona podía mantener en sí misma la dualidad de esclavitud y libertad. Muchos se beneficiarían de la «buena disposición» del propietario a manumitirlo en parte, de alcanzar ese estado tras el pago de una cantidad o tras la cesión de un «porcentaje» de su persona a otro. Esto lo constatamos cuando leemos la anotación de Alonso, «la mitad» esclavo de don Pedro de Sotomayor: «...baptizé Alonso, esclabo que era de Cansino, y es la mitad horro, y la otra mitad es de don Pedro de Sotomayor, es de edad de desiocho años, poco más o menos» ${ }^{133}$.

\section{BIBLIOGRAFÍA}

Alonso Acero, Beatriz, «Iglesia e Inquisición en la España norteafricana: Orán y Mazalquivir a fines del reinado de Felipe II», Hispania Sacra, 50 (101) (Madrid, 1998): 101-132.

Alonso Acero, Beatriz, Orán-Mazalquivir, 1589-1639: Una sociedad española en la frontera de Berbería, Madrid, Consejo Superior de Investigaciones Científicas, 2000.

Alonso Acero, Beatriz, «Heterodoxia e Inquisición en las sociedades hispanas de Berbería, siglos XVI-XVII», Hispania Sacra, 55 (112) (Madrid, 2003a): 481-499.

Alonso Acero, Beatriz, «Judíos en un mundo de frontera. Los recelos cristianos hacia la presencia judía en Orán», en Mercedes García-Arenal (ed.), Entre el Islam y Occidente. Los judios magrebies en la Edad Moderna, Madrid, Casa de Velázquez, 2003b; 223-243.

Alonso Acero, Beatriz, Cisneros y la conquista española del norte de África: cruzada, política y arte de la guerra, Madrid, Ministerio de Defensa, 2006a.

${ }^{131}$ AGS, Guerra Antigua, leg. 70-377.

132 AGS, Guerra Antigua, leg. 283, 334-336. Sobre el particular véase ALONSO ACERO, 2000: 265-271.

${ }^{133}$ ADT, Orán, 3455, fol. 154v. Orán, 24 de mayo de 1595. 
Alonso Acero, Beatriz, Sultanes de Berbería en tierras de la cristiandad. Exilio musulmán, conversión y asimilación en la Monarquía hispánica (siglos XVI y XVII), Barcelona, Bellaterra, 2006b.

Alonso Acero, Beatriz, «Orán, ciudad de frontera», en Ismet Terki Hassaine, Emilio Sola Castaño, Alejandro Ramón Díez Torre y Manuel Casado Arboniés (eds.), Las campanas de Orán, 1509-2009. Estudios en Homenaje a Fatma Benhamamouche, Alcalá de Henares, Universidad de Alcalá de Henares, 2012; 67-88.

Andújar Castillo, Francisco, «Los rescates de cautivos en las dos orillas del Mediterráneo y en el mar (alfías) en el siglo XVI», en Wolfgang Kaiser (coord.), Le comerce des captifs. Les intermédiaires dans l'échange et le rachat des prisionniers en Méditerranée, XVe-XVIIIe siècle, Roma, École Française de Rome, 2008; 135-164.

Austen, Ralph A., "The trans-Saharan slave trade. A tentative census», en Henry Gemery and Jan Hogendorn, The uncommon market. Essays in the Economic History of the Atlantic Slave Trade, New York, Academic Press, 1979; 23-76.

Bennassar, Bartolomé y Bennassar, Lucile, Los cristianos de Alá. La fascinante aventura de los renegados, Madrid, Nerea, 1989.

Bernabé-Pons, Luis F., «Taqiyya, niyya y el islam de los moriscos», Al-Qantara. Revista de Estudios Árabes, 34 (2) (Madrid, 2013): 419-527. doi: 10.3989/alqantara.2013.017

Bono, Salvatore, «Conversioni di Musulmani al Cristianesimo», en Bartolomé Bennassar et Robert Sauzet, Chrétiens et Musulmans à la Renaissance. Actes du 37e Colloque International du CESR (1994), Paris, Honoré Champion Éditeur, 1998; 429-446.

Bono, Salvatore, Un altro Mediterraneo. Una storia comune fra scontri e integrazioni, Perugia, Salerno Editrice, 2008.

Bouchareb, Ahmed, «Les conséquences socio-culterelles de la conquête ibérique du litoral marocain», en Mercedes García-Arenal y María Jesús Viguera (eds.), $R e$ laciones de la Península Ibérica con el Magreb (siglos XIII-XVI). Actas del Coloquio (Madrid, 17-18 de diciembre, 1987), Madrid, Consejo Superior de Investigaciones Científicas, 1988; 487-537.

Braudel, Fernand, La Méditerranée et le monde méditerranéen à l'époque de Philippe II, Paris, Armand Colin, 1949.

Bravo Caro, Juan Jesús, «El municipio de Málaga y la toma de Túnez (1535): los esclavos como botín de guerra», en El Mediterráneo: hechos de relevancia histórico-militar y sus repercusiones en España. V Jornadas Nacionales de Historia Militar, Sevilla, Universidad de Sevilla, 1998; 431-448.

Bravo Caro, Juan Jesús, «El reflejo de la esclavitud del Mediterráneo en los registros parroquiales oraneses», en Miguel Ángel de Bunes Ibarra y Beatriz Alonso Acero (coords.), Orán. Historia de la Corte Chica, Madrid, Polifemo, 2011; 143-171.

Bravo Caro, Juan Jesús, «Cautivos sardos y esclavos en Cerdeña: Una historia por hacer», en Identità e Frontiere. Politica, Economia e Società nel Mediterraneo (secc. XIV-XVIII), Milano, FrancoAngeli, 2014; 66-79.

Bravo Caro, Juan Jesús, «La conversión de esclavos y libres en las sinodales de la Iglesia española de la Edad Moderna», (en prensa). 
Caffiero, Marina, «Battesimi, libertà e frontiere. Conversioni di musulmani ed ebrei a Roma in età moderna», Quaderni Storici 126 (3) (Bologna, 2007): 819-839.

Caffiero, Marina, «Juifs et musulmans à Rome à l'époque moderne, entre resistanse, assimilation et mutations identitaires. Essai de comparaison», en Jocelyne Dakhlia et Bernard Vincent (dirs.), Les musulmans dans l'histoire de l'Europe. I. Une intégration invisible, Paris, Albin Michel, 2011; 593-609.

Cabrillana Ciézar, Nicolás, Santiago Matamoros, historia e imagen, Málaga, Diputación Provincial de Málaga, 1999.

Carabias Torres, Ana María, «La producción editorial sobre el Imperio Otomano y los turcos en España (1470-1850). Una investigación in fieri», Tiempos Modernos. Revista electrónica de Historia Moderna [en línea]. 20 (2010/1). Disponible en: http://www.tiemposmodernos.org/tm3/index.php/tm/article/view/205/262

Cortés López, José Luis, La esclavitud negra en la España peninsular del siglo XVI, Salamanca, Universidad de Salamanca, 1989.

Dakhlia, Jocelyne, «Assujettis au baptême? Récits de conversión au christianisme de musulmans dans les Iles Britanniques à l'époque moderne (XVIe-XVIIe siècle)», Jean-Paul Zúñiga (ed.), Negociar la obediencia. Autoridad y consentimiento en el mundo ibérico en la Edad Moderna, Granada, Comares, 2013; 161-187.

De Bunes Ibarra, Miguel Ángel, «La vida de los presidios del Norte de África», en Mercedes García-Arenal y María Jesús Viguera (eds.), Relaciones de la Península Ibérica con el Magreb..., 1988; 561-590.

De Bunes Ibarra, Miguel Ángel, «Reflexiones sobre la conversión al Islam de los renegados en los siglos XVI y XVII», Hispania Sacra, 42, 85 (Madrid, 1990): 181-198.

De Bunes Ibarra, Miguel Ángel, «Relaciones económicas entre la monarquía hispánica y el Islam en la época de Cervantes», Revista de Historia Económica Journal of Iberian and Latin America Economic History, Año 23 (Extra 1) (Madrid, 2005): 161-180.

De Bunes Ibarra, Miguel Ángel, «El Imperio otomano y la intensificación de la catolicidad de la monarquía hispana», Anuario de Historia de la Iglesia, 16 (Pamplona, 2007): 157-167.

De Bunes Ibarra, Miguel Ángel, «Estrategias de conversión del Islam español en el siglo XVI», en Juan Bosco Amores Carredano (ed.), Religión, herejías y revueltas sociales en Europa y América. VII Jornadas de Estudios Históricos del Departamento de Historia Medieval, Moderna y de América (Vitoria-Gasteiz, 8 al 10 de noviembre de 2005), Vitoria-Gasteiz, Universidad del País Vasco, 2008; 99-116.

De Bunes Ibarra, Miguel Ángel, «El control de la información del Mediterráneo desde Nápoles y Sicilia en la época de Felipe III», en José Martínez Millán y Manuel Rivero Rodríguez (coords.), Centros de Poder Italianos en la Monarquía Hispánica (siglos XV-XVIII), vol. 1, Madrid, Polifemo, 2010; 351-374.

De Bunes Ibarra, Miguel Ángel, «Diego Suárez Montañés, cronista y testigo de la historia de Orán-Mazalquivir», en Miguel Ángel de Bunes Ibarra y Beatriz Alon- 
so Acero (coords.), Orán. Historia de la Corte Chica, Madrid, Polifemo, 2011; 323-368.

De Bunes Ibarra, Miguel Ángel, «Orán, primera frontera hispano-turca del Mediterráneo», en Ismet Terki-Hassaine, Emilio Sola Castaño, Alejandro R. Díez Torre y Manuel Casado Arboniés (eds.), Las campanas de Orán, 1509-2009. Estudios en homenaje a Fatima Benhamamouche, Alcalá de Henares, Universidad de Alcalá, 2012; 55-66.

Díaz Borras, Andrés, «La Casa de Contratación de Orán y el cambio en la filosofía de las transacciones entre Berbería y Valencia, 1510-1514», Sharq Al-Andalus. Estudios mudéjares y moriscos, 9 (Alicante, 1992): 19-27.

Díaz Esteban, Fernando, «Una vacante de intérprete de lengua arábiga en Orán y dos versiones de los sucesos a que dio lugar en 1669», Anaquel de Estudios Árabes, 11 (Madrid, 2000): 257-275.

Dursteler, Eric R., Renegade women. Gender, identity and boundaries in the Early Modern Mediterranean, Baltimore, Johns Hopkins University Press, 2011.

Echevarría Arsuaga, Ana, «La conversion des chevaliers musulmans dans la Castille du XVe siècle», en Mercedes García-Arenal (dir.), Conversions islamiques. Identités religieuses en Islam méditerranéen, Paris, Maisonneuve et Larose, 2001; 119-138.

Eisenbeth, Maurice, «Les juifs en Algérie et en Tunisie à l'époque turque (15161830)», Revue Africaine, 96 (Alger, 1952): 114-187 y 343-384.

El Hamel, Chouki, Black Morocco. A History of Slavery, Race, and Islam, New York, Cambridge University Press, 2013.

Ennaji, Mohammed, Soldados, sirvientes y concubinas. La esclavitud en Marruecos en el siglo XIX, Granada, Almed, 1999.

Fernández Gallardo, Luis, «Santiago Matamoros en la historiografía medieval: origen y desarrollo de un mito nacional», Medievalismo. Boletín de la Sociedad Española de Estudios Medievales, 15 (Madrid, 2005): 139-174.

Fiume, Giovanna, Schiavitù mediterranee. Corsari, rinnegati e santi di età moderna, Milano, Bruno Mondadori, 2009.

Fiume, Giovanna, "Ignacio de las Casas, evangelizzatore "soave"», Rivista di Storia del Cristianísimo, 7 (1) (Brescia, 2010): 35-60.

García-Arenal, Mercedes, «L'estompe des identités en situation de conversión: Isaac Pallache, un converti insincère?», en Jocelyne Dakhlia et Wolfgang Kaiser (dirs.), Les musulmans dans l'histoire de l'Europe. II. Passages et contacts en Méditerranée, Paris, Albin Michel, 2013; 35-60.

García-Arenal, Mercedes y Rodríguez Mediano, Fernando, «Soumis à une seule loi. Les stratégies de Miguel de Luna, chrétien arabe de Grenada», en Michel Bertrand et Natividad Planas (eds.), Les sociétés de frontière de la Méditerranée à l'Atlantique (XVIe-XVIIIe siécle), Madrid, Casa de Velázquez, 2011; 23-41.

García Barranco, Margarita, «Correlaciones y divergencias en la representación de dos minorías: negroafricanos y moriscos en la literatura del Siglo de Oro», en Aurelia Martín Casares y Margarita García Barranco (comps.), La esclavitud ne- 
groafricana en la Historia de España. Siglos XVI y XVII, Comares, Granada, 2010; 151-171.

Gaytán, Pedro, Historia de Orán y su cerco... Los condes de Alcaudete en el Norte de África, Granada, Biblioteca Alcaudetense, 1998.

Gutiérrez Cruz, Rafael, Los presidios españoles del Norte de África en tiempo de los Reyes Católicos, Melilla, Consejería de Cultura, Educación, Juventud y Deporte de la Ciudad Autónoma de Melilla, 1997.

Gutiérrez Cruz, Rafael, «Abastecimiento y fiscalidad en el presidio de Honein en 1533», en El emperador Carlos y su tiempo. Actas IX Jornadas Nacionales de Historia Militar, Sevilla, Deimos, 2000; 621-630.

Gutiérrez Cruz, Rafael, «Abastecimiento, paga y fiscalidad en Orán y Mazalquivir (1529-1534)», Baetica. Estudios de Arte, Geografía e Historia, 24 (Málaga, 2012): 283-296.

Isom-Verhaaren, Chistine, Allies with the infidel. The Ottoman and French Alliance in the Sixteenth Century, London-New York, I.B. Tauris, 2011.

Jiménez de Gregorio, Fernando, «Relación de Orán por el vicario don Pedro Cantero Vaca (1631-1636)», Hispania. Revista Española de Historia tomo XXII, n. LXXXV (Madrid, 1962): 81-117.

Kouider, Métair, Oran. Une Ville de fortifications, Oran, Bel Horizon, 2013.

Lahon, Didier, «Exclusion, integration et métissage dans les confréries noires au Portugal (XVIe-XIXe siècles)», en Berta Ares Queija y Alessandro Stella (coords.), Negros, mulatos, zambaigos. Derroteros africanos en los mundos ibéricos, Sevilla, Escuela de Estudios Hispano-Americanos (C.S.I.C.), 2000; 275-311.

Lewis, Bernard, Race and slavery in the Middle East. An Historical Enquiry, New York, Oxford University Press, 1990.

López de Coca Castañer, José Enrique, «Orán y el comercio genovés en la transición a los tiempos modernos», Anuario de Estudios Medievales, 24 (Barcelona, 1994): 275-298.

López de Coca Castañer, José Enrique, «Converso, hidalgo, fraile y renegado: Don Juan de Granada Abencomixa», Historia. Instituciones. Documentos, 39 (Sevilla, 2012): 129-151.

Malki, Nordine, Razzia, butin et esclavage dans l'Oranie du XVIème siècle: D'aprés le manuscrit de Diego Suárez, Oran, Dar el Gharb, 2003.

Malki, Sofiane, «Orán, el espejo de otra España bajo el mando de Don Martín de Córdoba, conde de Alcaudete», en Ismet Teiki-Hassaine, Emilio Sola Castaño, Alejandro R. Díez Torre y Manuel Casado Arboniés (eds.), Las campanas de Orán, 1509-2009. Estudios en homenaje a Fatima Benhamamouche, Alcalá de Henares, Universidad de Alcalá, 2012; 155-168.

Martín Casares, Aurelia, La esclavitud en la Granada del siglo XVI. Género, raza y religión, Granada, Universidad de Granada, 2000a.

Martín Casares, Aurelia, "Cristianos, musulmanes y animistas en Granada: identidades religiosas y sincretismo cultural», en Berta Ares Queija y Alessandro Stella (coords.), Negros, mulatos, zambaigos. Derroteros africanos en los mundos ibéricos, Sevilla, Escuela de Estudios Hispano-Americanos (C.S.I.C.), 2000b; 207-221. 
Martín Casares, Aurelia, «Comba y Dominga: La imagen sexualizada de las negroafricanas en la Literatura de cordel de la España moderna», en Aurelia Martín Casares y Margarita García Barranco (comps.), La esclavitud negroafricana en la Historia de España. Siglos XVI y XVII, Comares, Granada, 2010; 173-188.

Martín Corrales, Eloy, Comercio de Cataluña con el Mediterráneo musulmán (siglos XVI-XVIII). El comercio con los «enemigos de la fe», Barcelona, Bellaterra, 2001.

Martín Corrales, Eloy, «Comercio en la frontera. Judíos magrebíes intermediarios en los intercambios mercantiles hispano-norteafricanos (ss. XVI-XVIII)», en Mercedes García-Arenal (ed.), Entre el Islam y Occidente. Los judios magrebies en la Edad Moderna, Madrid, Casa de Velázquez, 2003; 251-281.

Martínez Torres, José Antonio, Prisioneros de los infieles. Vida y rescate de los cautivos cristianos en el Mediterráneo musulmán (siglos XVI-XVII), Barcelona, Edicions Bellaterra, 2004.

Martínez Torres, José Antonio, Esclavos, Imperios, Globalización (1555-1778), Madrid, Consejo Superior de Investigaciones Científicas, 2010.

Mauny, Raymond, Les siècles obscurs de l'Afrique noire: histoire et archéologie, Paris, Fayard, 1970.

Méndez Rodríguez, Luis, «La esclavitud a través del Arte», en Laberintos de libertad. Entre la esclavitud del pasado y las nuevas formas de esclavitud del presente, Madrid, Ministerio de Educación, Cultura y Deporte, 2012; 39-71.

Méndez Rodríguez, Luis, «La esclavitud femenina: visiones iconográficas en la España moderna (1500-1800)», en Aurelia Martín Casares y Rocío Periáñez Gómez (eds.), Mujeres esclavas y abolicionistas en la España de los siglos XV-XIX, Ma$\mathrm{drid} /$ Frankfurt, Iberoamericana/Vervuert, 2014; 33-54.

Montojo Montojo, Vicente y Ruiz Ibáñez, José Javier, «Relaciones y agentes comerciales entre Orán y el reino de Murcia en la primera mitad del siglo XVII», Murgetana, 120 (Murcia, 2009): 111-127.

Moore, J. K. Jr., «Juxtaposing James the Greater: Interpreting the Interstices of Santiago as Peregrino and Matamoros», La Corónica. A Journal of Medieval Hispanic Languages, Literatures \& Cultures, 36(2) (Columbus, 2008): 313-344.

Oliver Asín, Jaime, Vida de Don Felipe de África, príncipe de Fez y Marruecos (1566-1621), estudio preliminar de Miguel Ángel de Bunes Ibarra y Beatriz Alonso Acero, Granada, Universidad de Granada, 2008.

Parente, Fausto, «La posizione giuridica dell'ebreo convertito della Controriforma. La bolla "Cupientes Iudaeos" (1542) e la successiva elaborazione dottrinale», Sefarad, 51 (2) (Madrid, 1991): 339-352.

Pestre de Almeida, Lilian, «De Fez à Loreto, en passant par Malte, avant le départ vers les Indes ou le trajet d'un prince marocain converti, selon Calderón de la Barca», RiMe. Revista dell'Istituto di Storia dell'Europa Mediterranea, 8 (Torino, 2012): 35-49.

Planas, Natividad, «Musulmans invisibles? Enquête dans des territoires insulaires du roi d'Espagne (XVIe-XVIIe siècle)», en Jocelyne Dakhlia et Bernard Vincent 
(dirs.), Les musulmans dans l'histoire de l'Europe. I. Une intégration invisible, Paris, Albin Michel, 2011; 557-592.

Plazolles Guillén, Fabienne, «Barcelona a finales de la Edad Media: ¿entre mestizaje y conservación biológica?», en Berta Ares Queija y Alessandro Stella (coords.), Negros, mulatos, zambaigos. Derroteros africanos en los mundos ibéricos, Sevi1la, Escuela de Estudios Hispano-Americanos (C.S.I.C.), 2000; 21-57.

Poutrin, Isabelle, Convertir les musulmans. Espagne, 1491-1609, Paris, Presses Universitaires de France, 2012.

Pulido Serrano, Juan Ignacio, «Consentir por necesidad. Los judíos de Orán en la Monarquía Católica durante los siglos XVI y XVII», en Mercedes García-Arenal (ed.), Entre el Islam y Occidente. Los judios magrebies en la Edad Moderna, Madrid, Casa de Velázquez, 2003; 201-222.

Quenum, Alphonse, Les Églises chrétiennes et la traite atlantique du XVe au XIXe siècle, Paris, Éditions Karthala, 2008.

Ricard, Robert, «Le problème de l'occupation restreinte dans l'Afrique du Nord (XVe-XVIIIe siècles)», Annales d'Histoire, Économique et Sociale, 8 (41) (Paris, 1936a): 426-437.

Ricard, Robert, «Les établissements européens en Afrique du Nord du XVe au XVIIIe siècle et la politique d'occupation restreinte», Revue Africaine, 79 (2) (Alger, 1936b): 687-688.

Rodríguez Mediano, Fernando, «Conversión, langue et histoire: la christianisation de la langue arabe dans l'Espagne moderne», en Jocelyne Dakhlia et Wolfgang Kaise (dirs.), Les musulmans dans l'histoire de l'Europe. II. Passages et contacts en Méditerranée, Paris, Albin Michel, 2013; 537-563.

Romanos, Melchora, «Teatro histórico y evangelización en El gran Príncipe de Fez de Calderón de la Barca», en Christoph Strosetzki (ed.), Actas del V Congreso Internacional de la Asociación Siglo de Oro (AISO). (Münster, 1999), Madrid, Iberoamericana, Vervuert Verlagsgesellschaft, 2001; 1142-1150.

Rosenberger, Bernard, «Mouriscos et elches: conversions au Maroc au debut du XVIe siècle», en Mercedes García-Arenal y María Jesús Viguera (eds.), Relaciones de la Península Ibérica con el Magreb..., 1988; 621-664.

Salinas, Alfred, Oran la Joyeuse. Mémoires franco-andalouses d'une ville d'Algérie, Paris, L’Harmattan, 2004.

Sánchez Belén, Juan Antonio, «La expulsión de los judíos de Orán en 1669», Espacio. Tiempo y Forma. Historia Moderna, 6 (Madrid, 1993): 155-197.

Sánchez Doncel, Gregorio, Presencia de España en Orán (1509-1792), Madrid, Estudio Teológico de San Ildefonso, 1991.

Sanz Hermida, Jacobo, «El gran turco se ha buelto christiano: la difusión de las conversiones musulmanas y su instrumentalización político-religiosa», en Pierre Civil, Françoise Crémoux y Jacobo Sanz (eds.), España y el mundo mediterráneo a través de las Relaciones de Sucesos (1500-1750). Actas del IV Coloquio Internacional sobre Relaciones de Sucesos (París, 23-25 de septiembre de 2004), Salamanca, Universidad de Salamanca, 2008; 287-298. 
Schaub, Jean-Frédéric, Les juifs du roi d'Espagne. Oran, 1509-1669), Paris, Hachette Littératures, 1999.

Sebag, Paul, Tunis au XVIIe siècle. Une cite barbaresque au temps de la course, Paris, L'Harmattan, 1989.

Sola, Emilio, Los que van y vienen: información y fronteras en el Mediterráneo clásico del siglo XVI, Alcalá de Henares, Universidad de Alcalá, 2005.

Stella, Alessandro, Histoires d'esclaves dans la Péninsule Ibérique, Paris, École des Hautes Études en Sciences Sociales, 2000.

Stella, Alessandro, «"Mezclándose carnalmente”, relaciones sociales, relaciones sexuales y mestizaje en Andalucía Occidental», en Berta Ares Queija y Alessandro Stella (coords.), Negros, mulatos, zambaigos. Derroteros africanos en los mundos ibéricos, Sevilla, Consejo Superior de Investigaciones Científicas, 2000; 175-189.

Stella, Alessandro, «Étre esclave et musulman en Espagne au temps de l'éradication des «mauvaises sectes»»», en Jocelyne Dakhlia et Bernard Vincent (dirs.), Les musulmans dans l'histoire de l'Europe. I. Une intégration invisible, Paris, Albin Michel, 2011; 457-469.

Stewart, Devin, «The identity of "the Mufti of Oran", Abu L- Abbas Ahmad b. Abi Jum'ah Al-Maghrawi Al-Wahrani (d. 917-1511)», Al-Qantara. Revista de Estudios Árabes, 27 (2) (Madrid, 2006): 265-301.

Suárez Montañés, Diego, Historia del maestre último que fue de Montesa y de su hermano don Felipe de Borja. La manera como gobernaron las memorables plazas de Orán y Mazalquivir, reinos de Tremecén y Ténez, en África, siendo allí capitanes generales, uno en pos del otro, como aqui se narra, edición y estudio preliminar por Miguel Ángel de Bunes Ibarra y Beatriz Alonso Acero, Valencia, Institució Alfons el Magnànim, 2005.

Tarruell Pellegrin, Cecilia, «Don Carlos de África, un caballero de Santiago atípico», en Miguel Ángel de Bunes Ibarra y Beatriz Alonso Acero (coords.), Orán. Historia de la Corte Chica, Madrid, Polifemo, 2011; 263-288.

Tarruell Pellegrin, Cecilia, «Presencia y permanencia de población musulmanaconversa tras las expulsiones: los conversos de origen berberisco u otomano», en Actas XII Simposio Internacional de Mudejarismo (Teruel, 14-16 de septiembre de 2011), Teruel, Centro de Estudios Mudéjares, 2013; 545-554.

Tarruell Pellegrin, Cecilia, «Peticionarios de Mercedes provenientes de tierras del Islam en la Corte de Madrid (finales siglo XVI-inicios siglo XVII)», en Ricardo Franch Benavent, Fernando Andrés Robres y Rafael Benítez Sánchez-Blanco (eds.), Cambios y resistencias sociales en la Edad Moderna. Un análisis comparativo entre el centro y la periferia mediterránea de la Monarquía Hispánica, Madrid, Silex, 2014a; 263-271.

Tarruell Pellegrin, Cecilia, «Servir tras un largo cautiverio: trayectorias de los soldados cautivados en defensa de la monarquía», en María Martínez Alcalde y José Javier Ruiz Ibáñez (eds.), Felipe II y Almazarrón: La construcción local de un Imperio global. Volumen 1: Vivir, defender y sentir la frontera, Murcia, Universidad de Murcia, 2014b; 293-310. 
Terki-Hassaine, Ismet, «Liberación de Orán y Mazalquivir: fruto de una larga lucha y difíciles negociaciones hispano-argelinas (1732-1792)», en Ismet TerkiHassaine, Emilio Sola Castaño, Alejandro R. Díez Torre y Manuel Casado Arboniés (eds.), Las campanas de Orán, 1509-2009. Estudios en homenaje a Fatima Benhamamouche, Alcalá de Henares, Universidad de Alcalá, 2012; 169-194.

Valensi, Lúcete, Ces étrangers familiers. Musulmans en Europe (XVIe-XVIIIe siècles), Paris, Payot, 2012.

Varriale, Gennaro, «Lugares paralelos: moros pero cristianos», en José F. Forniés Casals y Paulina Numhause (eds.), Escrituras Silenciadas: el paisaje como historiografía, Alcalá de Henares, Universidad de Alcalá, 2013; 361-379.

Vincent, Bernard, «Musulmans et conversion d'Espagne au XVIIe siècle», en Mercedes García-Arenal (dir.), Conversions islamiques. Identités religieuses en Islam méditerranéen, Paris, Maisonneuve et Larose, 2001; 193-205.

Vincent, Bernard, «Juifs et esclavage à Oran», en Mercedes García-Arenal (ed.), Entre el Islam y Occidente. Los judios magrebies en la Edad Moderna, Madrid, Casa de Velásquez, 2003; 245-252.

Vincent, Bernard, «La esclavitud en el Mediterráneo occidental (siglos XVI-XVIII)», en José Antonio Martínez Torres (coord.), Circulación de personas e intercambios comerciales en el Mediterráneo y en el Atlántico (siglos XVI, XVII y XVIII), Madrid, Consejo Superior de Investigaciones Científicas, 2008; 39-64.

Vincent, Bernard, «Conversion et contrainte: le cas des musulmans de la Monarchie Hispanique (XVIe-XVIIIe siècles)», Rivista di Storia del Cristianísimo, 7 (1) (Brescia, 2010): 61-70.

Vincent, Bernard, «Les musulmans dans l'Espagne moderne», en Jocelyne Dakhlia et Bernard Vincent (dirs.), Les musulmans dans l'histoire de l'Europe. I. Une intégration invisible, Paris, Albin Michel, 2011; 611-634.

Wolf, John B., The barbary coast. Algeria under the turks 1500-1830, New York, Norton, 1979.

Wright, John, The Trans-Saharan Slave Trade, London-New York, Routledge, 2007.

Recibido: $23 / 06 / 2014$

Aceptado: 25/02/2015 